\title{
The Emergence of Sex Differences in Personality Traits in Early Adolescence: A Cross-Sectional, Cross-Cultural Study
}

\author{
Marleen De Bolle and Filip De Fruyt \\ Ghent University \\ Corinna E. Löckenhoff \\ Cornell University \\ Maria E. Aguilar-Vafaie \\ Tarbiat Modares University \\ Hyun-nie Ahn \\ Ewha Womans University \\ Jüri Allik
}

University of Tartu and Estonian Academy of Sciences

Denis Bratko

University of Zagreb

Thomas R. Cain

Hampshire College

Niyada Chittcharat

Srinakharinwirot University

Ryan Fehr

University of Washington, Seattle

Michele J. Gelfand

University of Maryland

Sami Gülgöz

Koç University

Lee Jussim

Rutgers University and Stanford University

Goran Knežević

Belgrade University

Margarida P. Lima

University of Coimbra

Iris Marušić

Institute for Social Research in Zagreb, Zagreb, Croatia

Katsuharu Nakazato

Tokyo University of Social Welfare

Jose Porrata

San Juan, Puerto Rico

Anu Realo

University of Tartu
Robert R. McCrae

Baltimore, Maryland

Paul T. Costa Jr.

Duke University School of Medicine

Chang-kyu Ahn

Pusan National University

Lidia Alcalay

Pontificia Universidad Católica de Chile

Tatyana V. Avdeyeva

University of St. Thomas

Marina Brunner-Sciarra

Universidad Peruana Cayetano Heredia

Wayne Chan

Rutgers University

Jarret T. Crawford

The College of New Jersey

Emília Ficková

Slovak Academy of Sciences

Sylvie Graf

Academy of Sciences of the Czech Republic

Martina Hřebíčková

Academy of Sciences of the Czech Republic

Waldemar Klinkosz

The John Paul II Catholic University of Lublin

Nora Leibovich de Figueroa

University of Buenos Aires

Thomas A. Martin

Susquehanna University

Khairul Anwar Mastor

Universiti Kebangsaan Malaysia

Florence Nansubuga

Makerere University

Danka Purić

Belgrade University

Norma Reátegui

Universidad Peruana Cayetano Heredia 
Jean-Pierre Rolland

Université Paris Ouest Nanterre La Défense

Andrzej Sekowski

The John Paul II Catholic University of Lublin

Yoshiko Shimonaka

Bunkyo Gakuin University

Jerzy Siuta and Barbara Szmigielska

Jagiellonian University

Lei Wang

Peking University

\author{
Vanina Schmidt \\ University of Buenos Aires \\ Jane Shakespeare-Finch \\ Queensland University of Technology \\ Franco Simonetti \\ Pontificia Universidad Católica de Chile \\ Vitanya Vanno \\ Srinakharinwirot University \\ Michelle Yik \\ The Hong Kong University of Science and Technology
}

Antonio Terracciano

Florida State University College of Medicine

\begin{abstract}
Although large international studies have found consistent patterns of sex differences in personality traits among adults (i.e., women scoring higher on most facets), less is known about cross-cultural sex differences in adolescent personality and the role of culture and age in shaping them. The present study examines the NEO Personality Inventory-3 (McCrae, Costa, \& Martin, 2005) informant ratings of adolescents from 23 cultures $(N=4,850)$, and investigates culture and age as sources of variability in sex differences of adolescents' personality. The effect for Neuroticism (with females scoring higher than males) begins to take on its adult form around age 14. Girls score higher on Openness to Experience and Conscientiousness at all ages between 12 and 17 years. A more complex pattern emerges for Extraversion
\end{abstract}

\footnotetext{
Marleen De Bolle and Filip De Fruyt, Department of Develomental, Personality, and Social Psychology, Ghent University; Robert R. McCrae, Independent Practice, Baltimore, Maryland; Corinna E. Löckenhoff, Department of Human Development, Cornell University; Paul T. Costa Jr., Department of Psychiatry and Behavioral Sciences, Duke University School of Medicine; Maria E. Aguilar-Vafaie, Department of Psychology, Tarbiat Modares University; Chang-kyu Ahn, Department of Education, Pusan National University; Hyun-nie Ahn, Department of Psychology, Ewha Womans University; Lidia Alcalay, Escuela de Psicologia, Pontificia Universidad Católica de Chile; Jüri Allik, Department of Psychology, University of Tartu and Estonian Academy of Sciences; Tatyana V. Avdeyeva, Graduate School of Professional Psychology, University of St. Thomas; Denis Bratko, Department of Psychology, University of Zagreb; Marina Brunner-Sciarra, Instituto de Medicina Genetica, Universidad Peruana Cayetano Heredia; Thomas R. Cain, School of Cognitive Science, Hampshire College; Wayne Chan, Department of Psychology, Rutgers University; Niyada Chittcharat, Department of Psychology, Srinakharinwirot University; Jarret T. Crawford, Department of Psychology, The College of New Jersey; Ryan Fehr, Foster School of Business, University of Washington, Seattle; Emília Ficková, Institute of Experimental Psychology, Slovak Academy of Sciences; Michele J. Gelfand, Department of Psychology, University of Maryland; Sylvie Graf, Institute of Psychology, Academy of Sciences of the Czech Republic; Sami Gülgöz, College of Social Science and Humanities, Koç University; Martina Hřebíčková, Institute of Psychology, Academy of Sciences of the Czech Republic; Lee Jussim, Department of Psychology, Rutgers University and Center for Advanced Study in the Behavioral Sciences, Stanford University; Waldemar Klinkosz, Department of Psychology, The John Paul II Catholic University of Lublin; Goran Knežević, Department of Psychology, Belgrade University; Nora Leibovich de Figueroa, Research Institute, Department of Psychology, University of Buenos Aires; Margarida P. Lima, Research Centre of the Study and Cognitive-Behavioral Intervention, University of Coimbra; Thomas A. Martin, Department of Philosophy, Religion, and Classical Studies, Susquehanna University; Iris Marušić, Institute for Social Research in Zagreb, Zagreb, Croatia; Khairul Anwar Mastor, Personality Traits Orientation, Universiti Kebangsaan Malay-
}

sia; Katsuharu Nakazato, Faculty of Social Welfare, Tokyo University of Social Welfare; Florence Nansubuga, Institute of Psychology, Makerere University; Jose Porrata, Independent Practice, San Juan, Puerto Rico; Danka Purić, Department of Psychology, Belgrade University; Anu Realo, Department of Psychology, University of Tartu; Norma Reátegui, Department of Psychology, Universidad Peruana Cayetano Heredia; Jean-Pierre Rolland, Département de Sciences Psychologiques, Université Paris Ouest Nanterre La Défense; Vanina Schmidt, Research Institute, Department of Psychology, University of Buenos Aires; Andrzej Sekowski, Department of Psychology, The John Paul II Catholic University of Lublin; Jane Shakespeare-Finch, School of Psychology \& Counselling, Queensland University of Technology; Yoshiko Shimonaka, Department of Human Studies, Bunkyo Gakuin University; Franco Simonetti, Escuela de Psicologia, Pontificia Universidad Católica de Chile; Jerzy Siuta and Barbara Szmigielska, Institute of Psychology, Jagiellonian University; Vitanya Vanno, Department of Psychology, Srinakharinwirot University; Lei Wang, Department of Psychology, Peking University; Michelle Yik, Division of Social Science, The Hong Kong University of Science and Technology; Antonio Terracciano, Department of Geriatrics, Florida State University College of Medicine.

This study was supported by a research grant from the National Research Foundation - Flanders (Grant 1200613N) awarded to Marleen De Bolle. This research was supported in part by the Intramural Research Program of the National Institutes of Health, National Institute on Aging. Anu Realo and Jüri Allik were supported by grants from the Estonian Ministry of Education and Science (SF0180029s08 and IUT2-13). Martina Hřebíčková and Sylvie Graf were supported by a grant from the Czech Science Foundation (13-25656S) and a grant from the Institute of Psychology, Academy of Sciences of the Czech Republic (RVO: 68081740). Robert R. McCrae and Paul T. Costa, Jr., receive royalties from the NEO Inventories. Jean-Pierre Rolland receives royalties for NEO-PI-R and NEO-PI-3 from Hogrefe France.

Correspondence concerning this article should be addressed to Marleen De Bolle, Department of Developmental, Personality and Social Psychology, H. Dunantlaan 2, B-9000 Ghent, Belgium. E-mail: Marleen.DeBolle@UGent.be 
and Agreeableness, although by age 17, sex differences for these traits are highly similar to those observed in adulthood. Cross-sectional data suggest that (a) with advancing age, sex differences found in adolescents increasingly converge toward adult patterns with respect to both direction and magnitude; (b) girls display sex-typed personality traits at an earlier age than boys; and (c) the emergence of sex differences was similar across cultures. Practical implications of the present findings are discussed.

Keywords: personality, sex differences, adolescence, cross-cultural

Supplemental materials: http://dx.doi.org/10.1037/a0038497.supp

The literature shows that major changes in biological (Lenroot \& Giedd, 2010; Marshall \& Tanner, 1986), cognitive (Blakemore, Burnett, \& Dahl, 2010; Colom \& Lynn, 2004), and psychosocial (Hunter \& Youniss, 1982; Rice \& Mulkeen, 1995) functioning occur in adolescence that may, in turn, affect personality traits and their development. Because the timing of these changes tends to diverge for boys and girls (Blakemore et al., 2010; Lenroot \& Giedd, 2010; Marshall \& Tanner, 1986), adolescence is a key period for examining the emergence of sex differences in personality.

Available studies on sex differences in adolescents' personality traits often show conflicting results. Costa, McCrae, and Martin (2008), for instance, found that young adolescent girls were higher than boys in Extraversion and Openness (see also McCrae, Costa, \& Martin, 2005; McCrae et al., 2002), whereas Branje, Van Lieshout, and Gerris (2007) reported that boys tended to be more extraverted and open to experience than girls. McCrae and colleagues (2002) found higher levels of Agreeableness and Neuroticism in girls (see also Klimstra, Hale, Raaijmakers, Branje, \& Meeus, 2009), whereas Branje et al. (2007) found no sex differences on these two dimensions. Klimstra and colleagues (2009) have suggested that these inconsistencies might be explained by differences in populations or cultures sampled or by variations in the particular adolescent age groups selected. The current study therefore aims (a) to examine how and to what extent culture and age affect sex differences in adolescence, and (b) to report crosssectional age trends in sex differences in the personality traits of adolescents based on observer ratings obtained in 23 cultures around the world (Adolescent Personality Profiles of Cultures project [APPOC]; De Fruyt et al., 2009). We then compare these sex differences in adolescence with findings on college students and adults to describe sex differences from early adolescence through adulthood across cultures. To provide a comprehensive account, personality is considered according to the five-factor model (FFM; McCrae \& Costa, 2008) - that is, Neuroticism (N), Extraversion (E), Openness to Experience (O), Agreeableness (A), and Conscientiousness $(\mathrm{C})$ - and sex differences are examined at both the domain and facet levels of personality.

\section{The Role of Culture}

Studies of sex differences conducted in different cultures might well show divergent results. Every culture has distinct gender roles for males and females, but the specific behaviors and attitudes considered appropriate for the two sexes may widely differ. In traditional cultures, women may be confined to domestic roles of child rearing and housekeeping; in contemporary Western societies, women are actively encouraged to take on the historically masculine occupations of scientist and engineer. Eagly's (1987) social role model argues that these gender roles are internalized early in life and are the source of gender differences in personality. If so, there might be wide cultural variation in the traits that distinguish boys and girls.

One of the major tasks of child development is the acquisition of knowledge about how to behave in a sex-appropriate manner. In general, parents, peers, and social institutions encourage (and excuse) "manly" behavior in boys and "ladylike" behavior in girls, but they also implicitly acknowledge that sex roles are age-graded: A 3-year-old boy who cries will probably be comforted by parents, whereas a 13-year-old boy who cries may be the object of ridicule. Enculturation into gender roles is thus a developmental process, and there are cultural differences in the nature and timing of this process. In some preliterate societies, very young children are raised together, but at a certain age (7 to 10 in Sambia; Herdt, 1982), boys are taken from their mothers and raised in the company of other males. In contrast, in most Western societies, coeducational schools are the norm. As Maccoby and Jacklin (1987) noted, "cross-cultural and within-culture situational variations make a great deal of difference in the amount of interaction contact male and female children have with one another" (p. 282). If personality traits are influenced by such experiences, we might expect that sex differences would vary across cultures in their developmental course.

Clearly, one cannot examine hypotheses about cultural variations in sex differences in personality traits or their developmental course unless one samples a range of cultures. At the same time, it is important to note that cross-cultural studies are valuable even if no cultural variation is found. If studies are confined to a single culture, there is no way to determine whether sex differences are attributable to cultural norms, recent historical events, or human evolution (Buss, 1995, 1997). To the extent that similar patterns are seen despite differences in culture, biological and evolutionary theories of sex differences become more plausible.

Sex differences in college-age and adult personality have been systematically examined across a wide range of cultures (Costa, Terracciano, \& McCrae 2001; McCrae \& Terracciano, 2005b; Schmitt, Realo, Voracek, \& Allik, 2008). Results suggest that the overall pattern of sex differences is similar in most cultures if one considers only the direction of effects. For example, women are rated as higher than men in Neuroticism in 49 of 50 cultures (McCrae \& Terracciano, 2005a). There are, however, cultural differences in the magnitude of these differences, with smaller effects seen in traditional cultures (e.g., India, Morocco) and larger effects in modern, Western nations (e.g., England, Switzerland). This might represent a cultural effect on the expression of personality traits (Schmitt et al., 2008), or merely a cultural effect on the 
frame of reference chosen when describing men and women (Guimond et al., 2007).

Bleidorn et al. (2013) reported similar findings in a sample of individuals aged 16 to 40 years from 62 cultures. However, crosscultural studies of younger adolescents are limited. Soto, John, Gosling, and Potter (2011) used Internet data collected from respondents aged 10 to 65 years from English-speaking cultures, and reported that adolescence is a key period in which sex differences for several personality traits tend to emerge. Preliminary analyses of the data reported in the present study (see McCrae et al., 2010) suggested that sex differences among adolescents aged 12 to 17 were roughly similar to those seen in adults, and that-as with adults- greater gender differentiation was typically seen in modern, Western cultures. However, those analyses considered only broad indices of gender differences rather than individual domains and facets, and they did not consider the role of age within this key developmental period.

Therefore, the first research aim of the present study is to investigate whether culture and age contribute to the variability in sex differences in adolescent personality, using informant-rated cross-cultural personality data of adolescents obtained in 23 cultures around the world, including both English and non-English speaking cultures.

\section{The Timing of Sex Differences}

To formulate hypotheses regarding exactly when sex differences of personality might emerge during the course of adolescence, we draw on findings regarding adolescents' changes in biological (Marshall \& Tanner, 1986), cognitive (Colom \& Lynn, 2004), and psychosocial (Hunter \& Youniss, 1982; Rice \& Mulkeen, 1995) functioning. Because the timing of these changes tends to diverge for boys and girls, the resulting sex gap in these domains of functioning may also help to explain the emergence of sex differences in personality traits during adolescence.

The biological changes during adolescence, such as the hormone-driven development of secondary sex characteristics, typically begin around age 11 for girls and age 13 for boys (Marshall \& Tanner, 1986). These biological changes have been found to contribute to changes in how individuals behave and interact with the social environment. More specifically, whereas girls tend to display a stronger affiliative style than boys even before adolescence (characterized by a preference for close emotional communication, intimacy, and responsiveness within interpersonal relationships), this affiliative orientation intensifies during adolescence (Larson \& Richards, 1989). Research in nonhuman mammals has suggested the existence of biological processes (i.e., changes in circulating gonadal hormones) underlying this intensification of affiliative behavior (Cyranowski, Frank, Young, \& Shear, 2000). From a FFM perspective, affiliative behavior is closely linked to A. Therefore, it is expected that the sex differences for A (with females typically scoring higher than males) should already be observable at age 12 and become larger thereafter.

In addition, changes in circulating gonadal hormones during puberty are also found to have an impact on the central nervous system that relate to disturbances in mood (Susman, Nottelmann, Inoff-Germainz, Dorn, \& Chrousos, 1987). More specifically, research has demonstrated that these hormonal changes place girls at increased risk to develop depression in the face of negative interpersonal experiences or life events, contributing to the emergence of the sex gap for depression between the ages of 14 and 15 (Angold, Costello, Erkanli, \& Worthman, 1999; Angold, Costello, \& Worthman, 1998; Angold \& Worthman, 1993). Drawing from this literature and studies that demonstrate that internalizing problems (such as depression) are highly related within and across time with N (e.g., De Bolle, Beyers, De Clercq, \& De Fruyt, 2012), sex differences for $\mathrm{N}$ are expected to emerge around the age of 14 years.

Several researchers in the field have demonstrated that $\mathrm{E}$ includes different components that may display opposite sex differences (e.g., DeYoung, Quilty, \& Peterson, 2007; Roberts, Walton, \& Viechtbauer, 2006), so hypotheses concerning the emergence of sex differences for this personality domain are less clear-cut than for the other personality domains. From a conceptual point of view, E includes an energy component (including activity, positive emotions, and excitement seeking) and an interpersonal component (including warmth, gregariousness, and assertiveness). The energy component can be seen as conceptually opposite to anhedonia, a central feature of depression. Following this line of reasoning, it is expected that sex differences in the energy-related facets of $\mathrm{E}$ will appear around the age of 14 years. The interpersonal component, on the other hand, is more closely related to affiliative orientation. Therefore, it is hypothesized that the emergence of sex differences in the interpersonal facets of $\mathrm{E}$ mirrors the emergence of the sex gap in affiliative behavior, and thus will already be observable by age 12 .

Furthermore, it has been demonstrated that girls undergo a faster acceleration in cerebral cortical development than boys during early adolescence and remain in advance of boys until 14 to 15 years (Colom \& Lynn, 2004). As a result, girls are generally ahead of boys in intellectual and cognitive functioning during early adolescence (Silberman \& Snarey, 1993). From a FFM perspective, O tends to correlate highest with intelligence (Ackerman \& Hilsenroth, 2003; Moutafi, Furnham, \& Paltiel, 2005), and recently, a genetic basis of this phenotypic association has been suggested (Bratko, Butkovic, Vukasovic, Chamorro-Premuzic, \& von Stumm, 2012). In addition, substantial conceptual overlap exists between $\mathrm{C}$ and executive functioning, which is generally defined as the ability to engage in purposeful and planned behavior (Fuster, 2001), and includes the ability to organize, execute, persist, and regulate goal-directed behavior (Fuster, 2002). A recent study (Anderson, Anderson, Northam, Jacobs, \& Catroppa, 2001) examined developmental progressions in executive functioning through late childhood and early adolescence, and found some evidence of sex differences that mirrored (both in terms of timing and direction) those found for cerebral cortical developments. More specifically, around ages 12 or 13, girls were found to move from poorer to superior levels on a range of executive functioning tasks, compared with boys, though this effect appeared to diminish by age 15 . We therefore hypothesize that sex differences in $\mathrm{O}$ and $\mathrm{C}$ (with girls scoring higher than boys) will be particularly large in early adolescent years and become smaller afterward because of a catch-up development in boys. As part of the second research aim of the current study, we will describe how sex differences in personality unfold during adolescence, testing the hypotheses formulated above. 


\section{Assessment Concerns}

As in adulthood, personality traits in adolescence are conceptualized to be hierarchically organized, with each of the broad FFM dimensions comprising several more fine-grained personality traits or facets that capture unique information about behavior (Ashton, Jackson, Paunonen, Helmes, \& Rothstein, 1995; Costa \& McCrae, 1995), and allow a more complex and differentiated description of people's personality. In fact, research has demonstrated that the direction of sex differences might be distinct for facets within a particular domain (Costa et al., 2001; McCrae \& Terracciano, 2005a). It is therefore essential to supplement domain-level research with a facet-level description to enable a thorough understanding of sex differences in personality (Soto et al., 2011; Terracciano, McCrae, Brant, \& Costa, 2005). To date, however, only two studies (e.g., Costa et al., 2008; Soto et al., 2011) have investigated sex differences in adolescence at the more finegrained facet level of personality. Costa and colleagues (2008) found far fewer significant facet-level sex differences in early adolescence than have been observed in adulthood (Costa et al., 2001). When sex differences emerged in their data, these were typically found for feminine-typed facets (i.e., facets on which adult women typically score higher than men; N1: Anxiety; E1: Warmth; E2: Gregariousness; E6: Positive Emotions; O2: Aesthetics; O3: Feelings; A3: Altruism; and A6: Tender-Mindedness) but not for masculine-typed facets (i.e., facets on which adult men typically score higher than women; E3: Assertiveness; E5: Excitement Seeking; O5: Openness to Ideas; and C1: Competence). According to the authors, these results imply that girls aged 12 to 13 have begun to display higher levels of sex-typed personality traits, but that boys of this age have not (Costa et al., 2008). Soto and colleagues (2011) found girls to score higher on the facets of N (i.e., Depression and Anxiety) and A (i.e., Altruism and Compliance) from age 10 onward, whereas they began to score higher on the facet of E (i.e., Assertiveness and Activity) only from age 15. For $\mathrm{O}$ and $\mathrm{C}$, somewhat divergent sex patterns were observed: From age 15, girls appear to score higher on Aesthetics but lower on Ideas (facets of $\mathrm{O}$ ). At all ages during adolescence, girls were as high as boys on Self-Discipline but scored higher on Order (facets of $\mathrm{C}$ ).

There are also lingering concerns about measurement. Most extant studies (Klimstra et al., 2009; McCrae et al., 2002; Pullmann, Raudsepp, \& Allik, 2006; Soto et al., 2011) have asked adolescents to provide self-reports of personality and relied on measures developed for use in adults, which may be problematic. First, it appears that early adolescents may have difficulties with the vocabulary in some of the items, or that some items might refer to behavior infrequently observed in adolescents, resulting in reliability problems or a less clearly replicated factor structure (Allik, Laidra, Realo, \& Pullmann, 2004; De Fruyt et al., 2009). In line with this notion, Soto, John, Gosling, and Potter (2008) found that personality self-reports from children and adolescents are less reliable than adults' reports. Second, self-perceptions-at all ages - may be more influenced by motivational factors than otherperceptions (Funder \& Colvin, 1997), especially for highly evaluative traits. Although informant reports are not immune to certain biases or distortions (e.g., implicit personality theories), their strengths and limitations complement those of self-reports. As such, it is important (a) to use adolescent-friendly personality measures, and (b) to replicate self-reported sex differences in adolescence using non-self-reported data (Branje et al., 2007). The present study meets these needs by examining sex differences using informant-rated personality data on adolescents, obtained by means of the NEO Personality Inventory-3 (NEO-PI-3; McCrae, Costa, et al., 2005), a more readable version of the revised NEO-PI (NEO-PI-R) validated for the assessment of individuals as young as 12 . Most of the raters were college undergraduates, who should readily understand the language of the NEO-PI-3 and provide more reliable assessments than younger adolescents would.

\section{Research Objectives}

The current study aims to investigate two possible sources (i.e., culture and age) of inconsistencies that characterize the literature on adolescent sex differences in personality. In addition, the present study meets the need for systematic large-scale cross-cultural research, examining sex differences in adolescents aged 12 to 17 years from around the world, covering 23 cultures from Europe, Africa, South America, Middle East, and Asia, thereby including both English-speaking and non-English-speaking cultures. To offer a comprehensive and detailed account of sex differences in personality, the current study will provide an examination of sex differences in the five higher order domains and the 30 lower order facets assessed by the NEO-PI-3.

Cross-cultural research in college students and adults has shown some cultural variation in the magnitude of sex differences-with larger effects in modern, Western cultures-but the direction of effects is generally consistent across cultures. The current study will examine whether sex differences in adolescence are also consistent in direction across cultures.

It is further hypothesized that - across cultures-female adolescents will score higher than males on all five personality domains. Consistent with the literature on biological, cognitive, and psychosocial changes that occur in adolescent boys and girls, we hypothesize that girls will score higher on $\mathrm{N}$ and the energy facets of $\mathrm{E}$ from 14 years onward. Furthermore, it is expected that the sex differences for A (with females typically scoring higher than males) and the interpersonal facets of $\mathrm{E}$ will be apparent by age 12, and that sex differences in $\mathrm{O}$ and $\mathrm{C}$ (with girls scoring higher than boys) are particularly large in early adolescent years but become smaller afterward because of a catch-up trend in boys. At the facet level, some deviations from the general domain-level sex differences are expected. Consistent with the adult literature, girls are hypothesized to score higher on most facets, but boys are expected to score higher on E3: Assertiveness, E5: Excitement Seeking, C1: Competence, and O5: Ideas (McCrae \& Terracciano, 2005a). In line with the findings of Costa et al. (2008), and parallel to the sex gaps found for biological, cognitive, and psychosocial changes in adolescence (with girls generally outperforming same-aged boys), we expect that sex differences for feminine-typed personality traits will emerge at an earlier age than sex differences for masculinetyped personality traits.

\section{Method}

\section{Procedure and Participants}

The APPOC project is a continuation of the Personality Profiles of Cultures Project (PPOC; McCrae \& Terracciano, 2005a, 2005b) 
that focused on personality from young adulthood onward. Collaborators of the PPOC project and other interested investigators were invited to join the APPOC project, and were requested to collect informant ratings of 50 boys and 50 girls between 12 and 14 years, and 50 boys and 50 girls between 15 and 17 years of age.

Informants were usually undergraduate students enrolled in a psychology major at universities where APPOC collaborators were employed. They were, on average, 21.3 years old $(S D=3.9$; ranging from 15 to 66 years), with $64.7 \%$ females (ranging from $41.3 \%$ for Hong Kong to $88.1 \%$ for Argentina), reflecting the large proportion of females in undergraduate psychology programs. Overall, 95.6\% were native-born citizens, ranging from $83.1 \%$ (Serbia) to $100 \%$ (Estonia, Japan, Malaysia, Poland, Slovak Republic, and Turkey). When completing the NEO-Inventory, informants were asked to think of a boy or girl aged 12 to 14 years old or 15 to 17 years old whom they know well and who is a native-born citizen of the country they lived in. Questionnaires for each target category (i.e., boys between 12 and 14 years; girls between 12 and 14 years; boys between 15 and 17 years; girls between 15 and 17 years) were randomly distributed among informants, and each informant provided personality ratings for only one target. Participation was voluntary and anonymous (De Fruyt et al., 2009).

The total APPOC sample available for analysis included 2,526 adolescent males (mean age $=14.88, S D=1.75$ ) and 2,583 adolescent females (mean age $=14.90, S D=1.69$ ). For the present study, data from France was not taken into account, ${ }^{1}$ bringing the final sample to 4,850. A detailed description of the procedure and sample characteristics was provided in De Fruyt and colleagues (2009). A data quality index was calculated, based on four different indicators: the number of unscreened (i.e., valid plus invalid) protocols with more than 40 missing NEO items, the mean score on the validity check item for the unscreened protocols, the proportion of missing items within the screened protocols (subsequently replaced by the neutral response), and the proportion of screened protocols with indications of yea- or nay-saying. As reported by De Fruyt et al., all cultures showed reasonably highquality data in an absolute sense.

\section{Measures}

The NEO-PI-3 (McCrae, Costa, et al., 2005) includes 240 items that are scored on a 5-point Likert scale assessing 30 facet scales, organized under the five domains of N, E, O, A, and C. Data on reliability and validity are presented in the manual (McCrae \& Costa, 2010); details on translation for the APPOC project were given in De Fruyt and colleagues (2009). In addition, De Fruyt and colleagues reported good psychometric properties of NEO-PI-3 informant ratings of adolescents aged 12 to 17 years for the 23 cultures that are included in the current study, and demonstrated that means from NEO-PI-R and NEO-PI-3 scales are directly comparable at the culture level, suggesting that it may be possible to directly compare sex differences observed in the present study for adolescence with sex differences in adulthood found with the NEO-PI-R (Costa \& McCrae, 1992). Measurement invariance tests across the NEO-PI-R and NEO-PI-3 are reported in the Results section. $^{2}$

To examine the factor structure of the NEO-PI-3 informant reports in early adolescence, De Fruyt et al. (2009) extracted five principal components and rotated these toward the normative adult Form S NEO-PI-R structure (Costa \& McCrae, 1992). The results of these analyses revealed that the target structure was closely replicated, with all factor congruence coefficients above .95 and all variable congruence coefficients above .87. Similar analyses were also conducted within each culture. The within-culture total congruence coefficients were all above the .85 threshold that is considered indicative of factor replicability (Lorenzo-Seva \& ten Berge, 2006), except that of Malaysia (.84).

\section{Comparison Data}

The data collected within APPOC were compared with data from two published studies: (a) NEO-PI-R informant ratings of college-age and adult targets from the 50 cultures of the PPOC project (McCrae \& Terracciano, 2005a), and (b) NEO-PI-R selfreport data from college-age and adult respondents from 25 cultures (Costa et al., 2001).

\section{Statistical Analyses}

All analyses were performed on within-culture standardized $z$ scores. These scores were obtained by subtracting the mean from the raw scores and then dividing these scores by the standard deviation for each subsample (i.e., culture).

Measurement invariance. Before performing the main analyses, measurement invariance (MI) of the five-factor personality domains across sex groups (i.e., males vs. females), age groups (i.e., 12 years, 13 years, 14 years, 15 years, 16 years, and 17 years), cultures (i.e., 23 cultures), and measures (i.e., NEO-PI-R vs. NEOPI-3) $)^{2}$ was examined. The rationale for these analyses and detailed results are presented in the online supplemental materials.

Hypothesis testing. To examine whether culture contributes to the variability in sex differences observed in the present data, multilevel analyses were conducted, with individuals (Level 1) nested within cultures (Level 2). More specifically, 35 (five personality domains and 30 facets) multilevel models were estimated. In each of these models, intercept and sex were included in the model, thereby allowing the intercept to vary on Level 1 (within cultures) and Level 2 (between cultures), and the slope coefficient to vary on Level 2. In these models, the Level 2 (between culture) variance of sex is of interest.

To test whether age affects sex differences in the present data, Sex $\times$ Age interactions were tested by means of the procedure proposed by Aiken and West (1991). More specifically, 35 (five personality domains and 30 facets) hierarchical regression analyses were performed, with age and sex entered in Block 1 and the Sex $\times$ Age interaction effect entered in Block 2 . If the $F$-change

\footnotetext{
${ }^{1}$ For France, no information on the targets' age in years was available. Because sex differences are examined in the present manuscript for the age of 12 years, 13 years, . . ., and 17 years separately, data from France were omitted when conducting the analyses for the present study. As such, the present study uses data of 23 instead of 24 cultures from the APPOC project.

${ }^{2}$ All 240 NEO-PI-R items, together with the 37 NEO-PI-3 replacement items, were administered in the APPOC project. As such, both NEO-PI-R and NEO-PI-3 facet and domain scores could be calculated for the targets included in the APPOC project, and measurement invariance across the NEO-PI-R and NEO-PI-3 could be examined.
} 
statistic of Block 2 is significant, it can be concluded that age affects sex differences in the personality trait under consideration. In that case, simple slopes were tested for boys and girls separately (Aiken \& West, 1991).

Next, to examine the emergence of transcultural sex differences in personality within adolescence, we investigated sex differences at the domain and facet levels for adolescents aged 12 years, 13 years, ..., and 17 years in the combined sample. In addition, the correspondence of sex differences in adolescents, college-aged individuals, and adult individuals was investigated by calculating the correlations (across the 30 facets) between sex differences across age groups. Sex differences were calculated for the domains and the facets by subtracting males' $z$ scores from females' $z$ scores, resulting in $d$ effect size. Positive effect sizes mean that females score higher than males on the particular domain or facet, whereas negative effect sizes mean that males score higher than females on the particular domain or facet.

\section{Results}

\section{Preliminary Analyses: Testing for MI}

The complete results of the MI tests are included as online supplemental material. With regard to sex (i.e., males vs. females), results showed full uniqueness invariance for $\mathrm{N}$ and $\mathrm{A}$. Partial scalar invariance (although with the constraint of equal error variances) across sex was demonstrated for $\mathrm{E}$ and $\mathrm{O}$. More specifically, the intercept of E5: Excitement-Seeking and E2: Gregariousness, and the intercepts of O2: Aesthetics and O3: Feelings, were released in the model of $\mathrm{E}$ and $\mathrm{O}$, respectively, such that model fit was adequate and change in Comparative Fit Index (CFI) and standardized root mean square residual (SRMR) dropped below the respective cutoffs. For $\mathrm{C}$, metric invariance was obtained across sex.

The MI tests across age demonstrated full uniqueness invariance for $\mathrm{N}$ and $\mathrm{E}$. Partial scalar invariance across the six age groups (i.e., 12 years, 13 years, 14 years, 15 years, 16 years, 17 years) was found for $\mathrm{O}$ and $\mathrm{A}$. In the latter models, the intercepts of $\mathrm{O} 1$ : Fantasy and O6: Values, and the intercept of A1: Trust, had to be estimated freely in each age group to obtain a change in CFI and SRMR that did not exceed the respective cutoffs. For C, metric invariance across age groups was demonstrated. Model fit for A did not worsen significantly when error variances were additionally constrained to be equal across age groups.

Across cultures, full uniqueness invariance was obtained for $\mathrm{N}$, $\mathrm{A}$, and $\mathrm{C}$, and scalar invariance was demonstrated for E. Configural invariance was obtained for O: Releasing. All factor loadings with modification indices larger than 10 (i.e., factor loadings for O1: Fantasy in Estonia and Argentina, and factor loadings for O6: Values in the United States and Portugal) resulted in a change of SRMR that still exceeded the cutoff (although change in the CFI did not exceed the cutoff).

Finally, full uniqueness invariance across measures was obtained for all five personality factors. In combination, these results suggest that measurement invariance was sufficient to conduct the planned analyses, although observed levels of MI tended to be somewhat higher for certain domains $(\mathrm{N}, \mathrm{A})$.

\section{Culture and Age as Sources of Variability in Sex Differences}

The mean differences between female and male adolescents aged between 12 and 17 years in 23 cultures on the five domains and the 30 facets are provided in the online supplemental materials. Parallel to the findings in adults (Costa et al., 2001; McCrae \& Terracciano, 2005a), the magnitude of sex differences at the domain level within cultures was generally small, with most sex differences smaller than or close to one-quarter standard deviation, and the directions of these effects were generally uniform across cultures. As reported by McCrae and colleagues (2010), less developed countries (e.g., Peru, Uganda) generally showed smaller effects. The mean absolute $d$ s for the 30 facets ranged from .09 in Puerto Rico to .32 in the Czech Republic. Of the 690 sex differences at the facet level, 184 were statistically significant, and 133 of these were smaller than one-quarter standard deviation; only 31 were larger than one-half standard deviation.

Interestingly, opposite-sex differences were observed in some cultures for specific facets. More specifically, in Thailand, adolescent boys scored higher on E4: Activity and O3: Feelings than adolescent girls, whereas in Uganda, boys were higher on $\mathrm{O} 1$ : Fantasy and O4: Actions than girls. In Argentina, adolescent boys were significantly higher than adolescent girls on A4: Compliance. Malaysian adolescent boys, finally, were higher on O1: Fantasy than Malaysian adolescent girls. If replicated, these findings suggest that there may occasionally be cultural differences in the direction of sex differences. Overall, however, the results demonstrated cultural differences only in the magnitude of sex differences at the domain and facet levels.

Results of the multilevel analyses are presented in Table 1. T1 Because of the coding of sex $(0=$ male; $1=$ female $)$ and age (centered around age 12), the estimated fixed intercept can be interpreted as referring to the expected outcome for a 12-year-old male, expressed in within-culture standardized $z$ scores. The fixed sex parameter estimates reflect the degree to which females (compared with males) score higher (if the estimate has a positive sign) or lower (if the estimate has a negative sign) on the personality traits under consideration. The degree of within-cultural and between-cultural variability in the intercept are captured by the Level 1 and Level 2 random parameter estimates of the intercept, respectively. The Level 2 random parameter estimates of sex illuminate whether there is significant between-cultural variability in sex differences for the respective personality traits.

Table 1 shows that adolescent girls scored, on average, higher on all five personality domains and on most personality facets. Adolescent boys, however, were found to score higher on E5: Excitement-Seeking and O5: Ideas when compared with adolescent girls. No significant sex differences were observed for N5: Impulsivity, E4: Activity, O1: Fantasy, O6: Values, and A4: Compliance.

We calculated the proportion reduction in Level 1 variance to quantify the effect of sex on personality (see the online supplemental materials for more information regarding the calculation and interpretation of this multilevel effect size measure). At the domain level of personality, we found that sex explained $0.70 \%$, $0.30 \%, 1.61 \%, 0.40 \%$, and $1.71 \%$ of the variance in $\mathrm{N}, \mathrm{E}, \mathrm{O}, \mathrm{A}$, and $\mathrm{C}$, respectively. The proportion of variance in the facets of $\mathrm{N}$ explained by sex was found to vary between $0.00 \%$ (N5: Impul- 
Table 1

Results of the Multilevel Analyses to Test for the Effect of Culture on Sex Differences in Personality Traits

\begin{tabular}{|c|c|c|c|c|c|}
\hline \multirow[b]{3}{*}{ NEO-PI-3 } & & & \multicolumn{3}{|c|}{ Random parameters } \\
\hline & \multicolumn{2}{|c|}{ Fixed parameters } & \multirow{2}{*}{$\frac{\text { Level } 1}{\sigma_{\text {Intercept }}^{2}}$} & \multicolumn{2}{|c|}{ Level 2} \\
\hline & Intercept & Sex & & $\sigma_{\text {Intercept }}^{2}$ & $\sigma_{\text {Sex }}^{2}$ \\
\hline $\mathrm{N}$ & $-.09^{* * * *}$ & $.17^{\text {****** }}$ & $.99^{\text {****** }}$ & .00 & .00 \\
\hline $\mathrm{E}$ & $-.06^{* *}$ & $.12^{* *}$ & $.99^{* * * *}$ & .00 & .00 \\
\hline $\mathrm{O}$ & $-.13^{* * * *}$ & $.25^{* * * *}$ & $.98^{* * * *}$ & .00 & .00 \\
\hline A & $-.07^{* * * *}$ & $.13^{* * * *}$ & $.99^{* * * *}$ & $.00^{* * * *}$ & $.00^{* * * *}$ \\
\hline $\mathrm{C}$ & $-.13^{* * *}$ & $.26^{* * * *}$ & $.98^{* * * *}$ & $.00^{* * * *}$ & $.00^{* * * *}$ \\
\hline N1 & $-.15^{* * * *}$ & $.29^{* * * *}$ & $.97^{* * * *}$ & .00 & .00 \\
\hline N2 & $-.05^{* * *}$ & $.10^{* * *}$ & $.99^{* * * *}$ & .00 & .00 \\
\hline N3 & $-.07^{* * * *}$ & $.14^{* * * * *}$ & $.99^{* * * * *}$ & .00 & .00 \\
\hline N4 & $-.05^{* *}$ & $.09^{* *}$ & $.99^{* * * *}$ & .00 & .00 \\
\hline N5 & .01 & -.03 & $1.00^{\text {****** }}$ & .00 & .00 \\
\hline N6 & $-.07^{* * * *}$ & $.14^{* * * * *}$ & $.99^{* * * * *}$ & .00 & .00 \\
\hline E1 & $-.09^{* * * *}$ & $.17^{* * * * *}$ & $.99^{* * * *}$ & .00 & .00 \\
\hline E2 & $-.12^{* * * *}$ & $.25^{* * * *}$ & $.98^{* * * *}$ & .00 & .00 \\
\hline E3 & $-.05^{* * * *}$ & $.09^{* * *}$ & $.99^{* * * *}$ & .00 & .00 \\
\hline E4 & -.03 & .06 & $.99^{* * * *}$ & .00 & .00 \\
\hline E5 & $.13^{* * * *}$ & $-.26^{* * * *}$ & $.98^{* * * *}$ & .00 & .00 \\
\hline E6 & $-.10^{* * * *}$ & $.20^{* * * *}$ & $.99^{* * * *}$ & .00 & .00 \\
\hline $\mathrm{O} 1$ & -.02 & .05 & $1.00^{\text {******* }}$ & .00 & .00 \\
\hline $\mathrm{O} 2$ & $-.25^{* * * *}$ & $.49^{* * * * *}$ & $.93^{* * * *}$ & .00 & .00 \\
\hline O3 & $-.18^{* * * *}$ & $.35^{* * * *}$ & $.96^{* * * *}$ & .00 & .00 \\
\hline $\mathrm{O} 4$ & $-.05^{* * *}$ & $.10^{*}$ & $.99^{* * * * *}$ & .00 & .00 \\
\hline O5 & $.04^{*}$ & $-.08^{*}$ & $.99^{* * * * *}$ & .00 & .00 \\
\hline O6 & -.00 & .01 & $1.00^{* * * * *}$ & .00 & .00 \\
\hline A1 & $-.05^{* * *}$ & $.09^{* *}$ & $.99^{* * * * *}$ & .00 & .00 \\
\hline A2 & $-.04^{* *}$ & $.07^{* * *}$ & $.99^{* * * *}$ & $.00^{* * * *}$ & $.00^{* * * *}$ \\
\hline A3 & $-.05^{*}$ & $.09^{*}$ & $.99^{* * * *}$ & .00 & .00 \\
\hline A4 & -.01 & .02 & $1.00^{* * * *}$ & .00 & .00 \\
\hline A5 & $-.04^{*}$ & $.08^{*}$ & $.99^{* * * *}$ & .00 & .00 \\
\hline A6 & $-.13^{* * * *}$ & $.26^{* * * *}$ & $.98^{* * * *}$ & .00 & .00 \\
\hline $\mathrm{C} 1$ & $-.05^{* * * *}$ & $.10^{* * * * *}$ & $.99^{* * * *}$ & $.00^{* * * * *}$ & $.00^{* * * *}$ \\
\hline $\mathrm{C} 2$ & $-.16^{* * *}$ & $.32^{* * * *}$ & $.97^{* * * * *}$ & .00 & .00 \\
\hline C3 & $-.14^{* * * *}$ & $.27^{* * * * *}$ & $.98^{\text {******* }}$ & .00 & .00 \\
\hline $\mathrm{C} 4$ & $-.11^{* * * *}$ & $.22^{* * * * *}$ & $.98^{\text {***** }}$ & .00 & .00 \\
\hline $\mathrm{C} 5$ & $-.11^{* * * *}$ & $.23^{* * * *}$ & $.98^{* * * *}$ & .00 & .00 \\
\hline C6 & $-.09^{* * * *}$ & $.19^{* * * * *}$ & $.99^{* * * *}$ & .00 & .00 \\
\hline
\end{tabular}

Note. NEO-PI-3 = NEO Personality Inventory-3; Level 1 = within cultures; Level 2 = between cultures; $\mathrm{N}=$ Neuroticism; $\mathrm{E}=$ Extraversion; $\mathrm{O}=$ Openness; $\mathrm{A}=$ Agreeableness; $\mathrm{C}=$ Conscientiousness; $\mathrm{N} 1=$ Anxiety; N2 = Angry Hostility; N3 = Depression; N4 = SelfConsciousness; N5 = Impulsiveness; N6 = Vulnerability; E1 = Warmth; $\mathrm{E} 2=$ Gregariousness; E3 = Assertiveness; E4 = Activity; E5 = Excitement-Seeking; E6 = Positive Emotions; O1 = Fantasy; O2 = Aesthetics; $\mathrm{O} 3=$ Feelings; O4 = Actions; O5 = Ideas; O6 = Values; A1 = Trust; $\mathrm{A} 2=$ Straightforwardness; A3 = Altruism; A4 = Compliance; A5 = Modesty; A6 = Tender-Mindedness; $\mathrm{C} 1=$ Competence; $\mathrm{C} 2=$ Order; C3 = Dutifulness; C4 = Achievement Striving; C5 = Self-Discipline; C6 $=$ Deliberation.

${ }^{*} p<.05 .{ }^{* *} p<.01 .^{* * * *} p<.001$.

siveness) and $2.11 \%$ (N1: Anxiety). The proportion of variance in the facets of E explained by sex varied between $0.10 \%$ (E4: Activity) and $1.61 \%$ (E5: Excitement-Seeking), whereas sex explained between $0.00 \%$ (O1: Openness to Fantasy and O6: Openness to Values) and $6.13 \%$ (O2: Openness to Aesthetics) of the variance in the facets of O. Finally, sex explained between $0.00 \%$ (A4: Compliance) and 1.71\% (A6: Tender-Mindedness), and between $0.20 \%$ (C1: Competence) and $2.51 \%(\mathrm{C} 2$ : Order) of the variance in the facets of $\mathrm{A}$ and $\mathrm{C}$, respectively.
Table 1 also shows no substantial between-culture variability in these sex differences. Although the results showed that A, C, A2: Straightforwardness, and C1: Competence varied significantly across cultures, the magnitude of these effects appeared to be negligible (.00). Cultures tend to show sex differences that are

Table 2

Results of the Hierarchical Regression Analyses and Simple Slopes Analyses to Test for the Effect of Age on Sex Differences in Personality Traits

\begin{tabular}{|c|c|c|c|c|}
\hline \multirow[b]{2}{*}{ NEO-PI-3 } & \multicolumn{2}{|c|}{$\begin{array}{l}\text { Hierarchical regression } \\
\qquad F \text { change }\end{array}$} & \multicolumn{2}{|c|}{ Simple slopes } \\
\hline & Block 1 & Block 2 & $\mathrm{~B}$ girls & B boys \\
\hline $\mathrm{N}$ & $38.42^{* * *}$ & $5.99^{*}$ & $-.06^{* *}$ & $-.13^{* * * *}$ \\
\hline $\mathrm{E}$ & $8.20^{* * * *}$ & .00 & & \\
\hline $\mathrm{O}$ & $40.70^{* * * * *}$ & .58 & & \\
\hline A & $16.09^{* * * *}$ & .97 & & \\
\hline $\mathrm{C}$ & $61.65^{* * * *}$ & 1.83 & & \\
\hline N1 & $61.48^{* * * *}$ & $9.85^{* *}$ & -.02 & $-.11^{\text {****** }}$ \\
\hline N2 & $23.74^{* * * *}$ & .62 & & \\
\hline N3 & $12.37^{\text {***** }}$ & 3.64 & & \\
\hline N4 & $23.08^{* * * * *}$ & 2.36 & & \\
\hline N5 & $20.35^{\text {**** }}$ & .52 & & \\
\hline N6 & $37.27^{* * * * *}$ & $7.70^{\text {*** }}$ & $-.06^{* *}$ & $-.14^{* * * *}$ \\
\hline E1 & $18.19^{* * * *}$ & .14 & & \\
\hline E2 & $36.12^{* * * *}$ & .83 & & \\
\hline E3 & $5.57^{* * *}$ & $4.08 *$ & -.04 & .02 \\
\hline E4 & $6.07^{* * *}$ & .40 & & \\
\hline E5 & $40.25^{* * * *}$ & .05 & & \\
\hline E6 & $27.14^{* * * *}$ & $5.63^{*}$ & -.00 & $-.07^{* * *}$ \\
\hline $\mathrm{O} 1$ & $32.44^{* * * *}$ & 2.92 & & \\
\hline $\mathrm{O} 2$ & $161.91^{* * * *}$ & $4.66^{*}$ & .00 & $.06^{* * *}$ \\
\hline $\mathrm{O} 3$ & $80.16^{* * * *}$ & .62 & & \\
\hline $\mathrm{O} 4$ & $7.01^{* * *}$ & .01 & & \\
\hline O5 & $3.41^{*}$ & $4.47^{*}$ & $-.04^{*}$ & .02 \\
\hline O6 & $21.56^{* * * *}$ & .02 & & \\
\hline A1 & $11.34^{* * * *}$ & .17 & & \\
\hline A2 & $15.35^{\text {**** }}$ & 1.21 & & \\
\hline A3 & $8.93^{* * * *}$ & .09 & & \\
\hline A4 & $4.47^{*}$ & .22 & & \\
\hline A5 & $12.57^{* * * * *}$ & 3.54 & & \\
\hline A6 & $44.75^{* * * *}$ & .01 & & \\
\hline $\mathrm{C} 1$ & $16.15^{\text {**** }}$ & 1.81 & & \\
\hline $\mathrm{C} 2$ & $76.53^{* * * *}$ & .54 & & \\
\hline $\mathrm{C} 3$ & $60.63^{* * * *}$ & 1.65 & & \\
\hline $\mathrm{C} 4$ & $37.76^{* * * *}$ & $4.24^{*}$ & .02 & $.08^{* * *}$ \\
\hline C5 & $49.73^{* * * *}$ & 1.53 & & \\
\hline C6 & $32.56^{* * * * *}$ & 3.13 & & \\
\hline
\end{tabular}

Note. Block 1 includes age and sex $\left(d f_{1}=2, d f_{2}=4749\right)$; Block 2 includes the Age $\times$ Sex interaction $\left(d f_{1}-1 ; d f_{2}=4748\right)$. Simple slopes were only tested and reported if $F$ change of Block 2 was significant. NEO-PI-3 = NEO Personality Inventory-3; $\mathrm{B}$ girls $=$ unstandardized estimate for the main effect of age in the model with "girls" as the reference group of sex; B boys = unstandardized estimate for the main effect of age in the model with "boys" as the reference group of sex; $\mathrm{N}=$ Neuroticism; $\mathrm{E}=$ Extraversion; $\mathrm{O}=$ Openness; $\mathrm{A}=$ Agreeableness; $\mathrm{C}=$ Conscientiousness; N1 = Anxiety; N2 = Angry Hostility; N3 = Depression; N4 = Self-Consciousness; N5 = Impulsiveness; N6 = Vulnerability; $\mathrm{E} 1$ = Warmth; E2 = Gregariousness; E3 = Assertiveness; E4 = Activity; E5 = Excitement-Seeking; E6 = Positive Emotions; O1 = Fantasy; O2 = Aesthetics; O3 = Feelings; O4 = Actions; O5 = Ideas; O6 = Values; $\mathrm{A} 1$ = Trust; A2 = Straightforwardness; A3 = Altruism; A4 = Compliance; $\mathrm{A} 5=$ Modesty $; \mathrm{A} 6=$ Tender-Mindedness; $\mathrm{C} 1=$ Competence; $\mathrm{C} 2=$ Order; $\mathrm{C} 3=$ Dutifulness; $\mathrm{C} 4=$ Achievement Striving; $\mathrm{C} 5=$ SelfDiscipline; $\mathrm{C} 6=$ Deliberation.

${ }^{*} p<.05$. $^{* * *} p<.01{ }^{* * * *} p<.001$ 

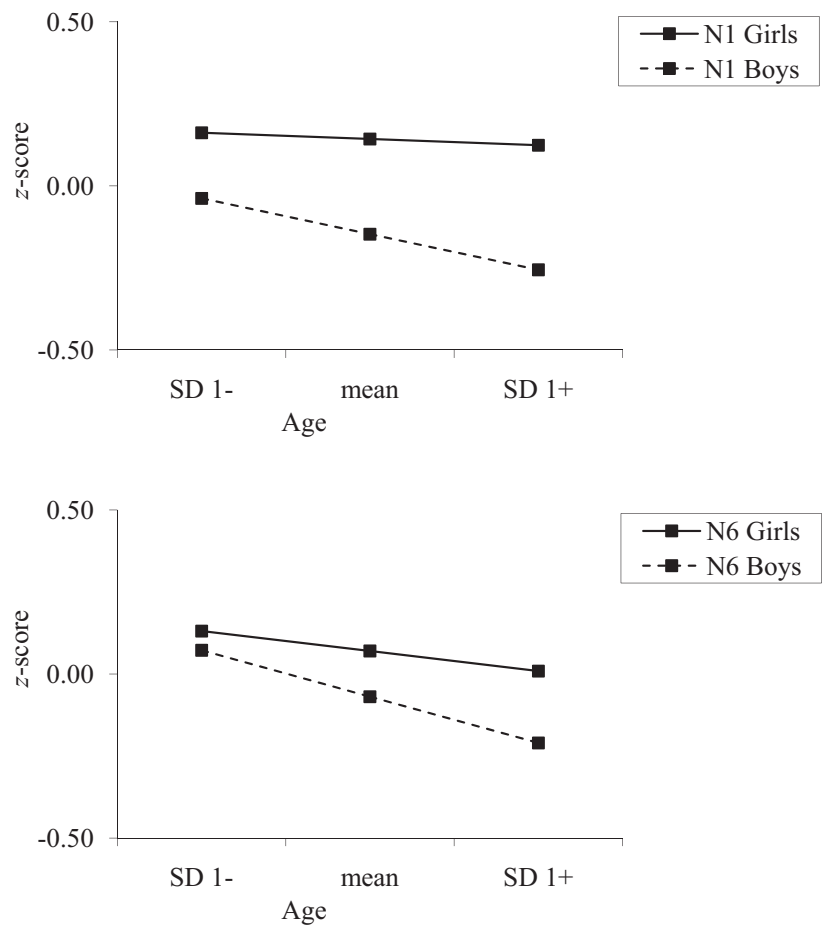

Figure 1. Predicted $z$ scores for N1: Anxiety (upper panel) and N6: Vulnerability (bottom panel) for girls and boys aged 12 to 17 years.

qualitatively the same, even though there is some quantitative variation in effect magnitude.

Because these results illustrate that culture is not a substantial predictor of adolescent sex difference in personality, it is appropriate to perform an examination of Age $\times$ Sex interaction effects across cultures according to the procedure proposed by Aiken and West (1991). The results of the hierarchical regression analyses (see Table 2) demonstrated significant Age $\times$ Sex interaction effects for $\mathrm{N}$ but not for the other personality domains. At the facet level, significant Age $\times$ Sex interaction effects were found for N1: Anxiety, N6: Vulnerability, E3: Assertiveness, E6: Positive Emotions, O2: Aesthetics, O5: Ideas, and C4: Achievement Striving.

According to the simple slope analyses (see Table 2), both boys and girls tend to display lower scores on $\mathrm{N}$ with increasing age, but this effect was stronger in boys than in girls. As a result, sex differences in $\mathrm{N}$ became more pronounced from age 12 to 17 .

F1-4 Figures 1, 2, 3, and 4 display the significant Age $\times$ Sex effects for the facets of $\mathrm{N}, \mathrm{E}, \mathrm{O}$, and $\mathrm{C}$, respectively. These figures illustrate that sex differences for N1, N6, E6, and O5 became larger, whereas sex differences for E3, O2, and C4 became smaller in adolescents aged 12 to 17 years.

\section{Transcultural Sex Differences}

Overall, the multilevel analyses did not reveal substantial between-culture variability of sex differences in personality. Therefore, it is appropriate to collapse across cultures and take a look across cultures at the emergence of sex differences in personality during adolescence.

Table 3 reports sex differences of the NEO-PI-3 domain and facet scales, expressed in $d$ effect size (i.e., differences between females' and males' $z$ scores). A positive effect size means that females score higher than males on a particular domain or facet. For comparative purposes, Table 3 also reproduces data from Costa and colleagues (2001) and McCrae and Terracciano (2005a), which examined sex differences in college students and adults.

As reported in Table 3, there were no sex differences in $\mathrm{N}$ at ages 12 and 13, but from age 14 onward, girls scored significantly higher than boys. Girls tended to score higher than boys also on the other domains, with effects most consistent for $\mathrm{O}$ and $\mathrm{C}$.

The emerging domain-level sex difference for $\mathrm{N}$ was reflected in the facet results, especially for N1: Anxiety, N3: Depression, and N6: Vulnerability. On these scales, the sex differences were mostly null in the 12- and 13-year-old groups, whereas girls scored substantially higher in the 15- to 17-year-old groups. The sex difference for N2: Angry Hostility, however, was nonsignificant at age 17. These findings demonstrated that the sex differences for $N$ are starting to emerge from age 14 .

With regard to the sex differences for the facets of E, girls were found to score higher than boys on E1: Warmth and E2: Gregariousness at all ages from early to middle adolescence (except at age 13). The sex difference for E5: Excitement Seeking, with males scoring higher than females-which is consistently found for college-aged and adult targets-could already be observed from age 12 (although no such sex difference was found at age 15 and 16). For E3: Assertiveness, girls appeared to score higher than boys at early adolescent age. By age 17 , however, this sex difference had disappeared, possibly transitioning toward the inverse sex difference for E3: Assertiveness (i.e., males scoring higher than females) that is observed from college age onward. Finally, al-
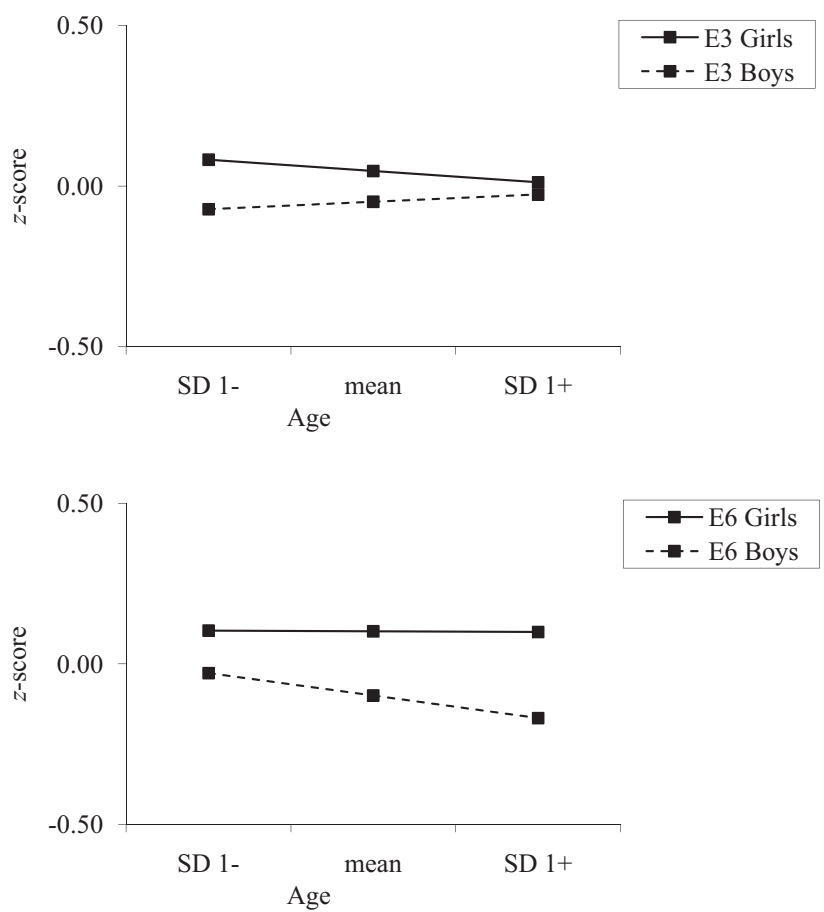

Figure 2. Predicted $z$ scores for E3: Assertiveness (upper panel) and E6: Positive Emotions (bottom panel) for girls and boys aged 12 to 17 years. 

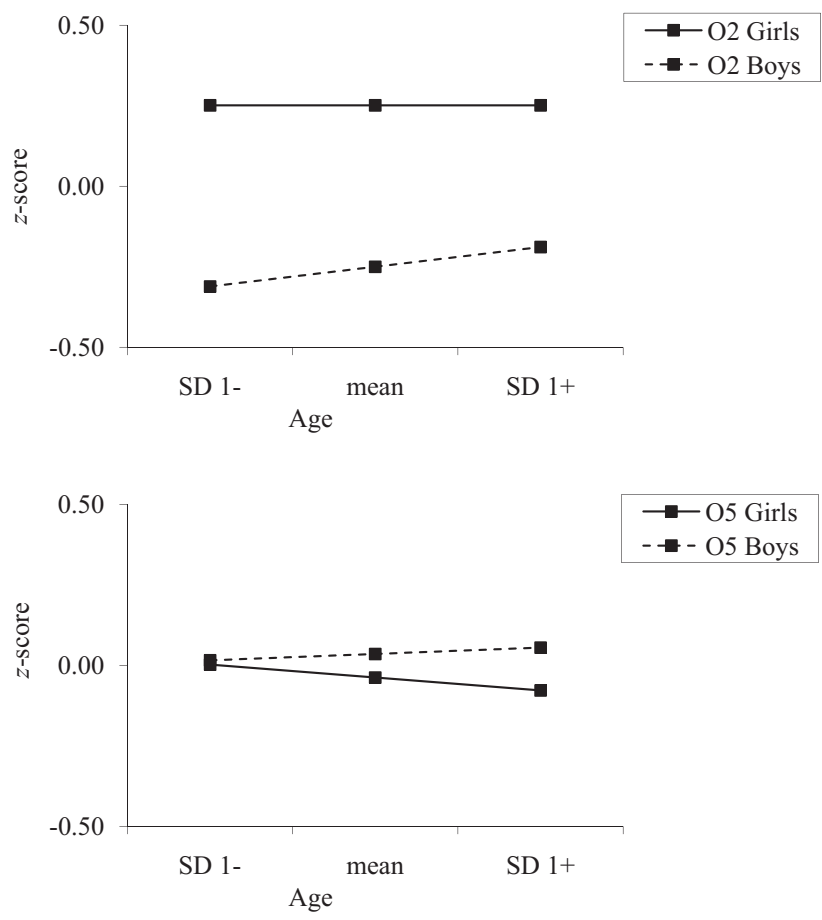

Figure 3. Predicted $z$ scores for O2: Aesthetics (upper panel) and O5: Ideas (bottom panel) for girls and boys aged 12 to 17 Year.

though girls scored already higher than boys on E6: Positive Emotions at age 12 and 14, this sex difference only became substantial from age 16. As such, by age 17, the adolescent sex differences in $\mathrm{E}$ were very close to those observed in adulthood, except for E3: Assertiveness. In adulthood, men score typically higher on this facet compared with women. In our adolescent sample, however, this sex difference had not yet emerged.

The domain-level finding that girls were generally more open to experience at age 12 to 17 years appeared to be mainly attributable to the relatively strong sex differences for the facets O2: Aesthetics and O3: Feelings. Furthermore, the results demonstrated that the sex difference pattern that is found in college aged and adult targets for O5: Ideas, with men scoring higher than women, began to show by age 17 . In all, most salient sex differences that were observed for $\mathrm{O}$ in adulthood had already developed by age 17 .

The facet-level findings for A show that girls consistently scored higher than boys on A6: Tender-Mindedness from age 12 to 17. Before age 17, few additional sex differences emerged for the other facets of A. At the age of 17 years, girls scored higher on all but one (i.e., A4: Compliance) of the facets of A. As such, by age 17, the sex differences for A had largely taken on their adult form.

The facet-level findings for C, finally, demonstrate that girls had higher scores than boys on all facets of $\mathrm{C}$ at age 12,13 , and 14 . No significant differences were found between both sexes for $\mathrm{C} 1$ : Competence and C4: Achievement Striving at age 15, and in addition for C5: Self-Discipline and C6: Deliberation at age 16. At age 17, girls again score higher on all facets of $\mathrm{C}$ (except for $\mathrm{C} 1$ : Competence). A remarkable finding is that although sex differences for the $\mathrm{C}$ facets tended to decline with increasing age during adolescence, adolescent girls aged 17 years still had considerably higher scores than boys on the facets of $\mathrm{C}$ (except for $\mathrm{C} 1$ : Competence), whereas such sex differences are not observed in adulthood. At the same time, the sex difference for $\mathrm{C} 1$ : Competencewith men scoring higher than women-was not yet found among adolescents.

As in college age and adulthood, sex differences appeared to be relatively subtle, as most were close to one-quarter standard deviation in magnitude. However, $\mathrm{O} 2$ and $\mathrm{O} 3$ showed effects as large as $d=.73$ for $\mathrm{O} 2$ : Aesthetics and .57 for O3: Feelings. Nevertheless, the median absolute value of sex differences on the 30 facets across ages ranged from .09 (13 years) to .17 (15 years) in the present sample. This demonstrates that in adolescence, as in adulthood, the score distributions of personality traits for the two sexes overlap very substantially.

Correlations among the columns of sex differences at the facet level are given in Table 4. These suggest that the pattern of sex T4 differences in adolescence were highly similar from age 12 to 17 years. However, sex differences in 12- to 13-year-old adolescents were only moderately similar to those found in adulthood, $r \mathrm{~s}=.19$ to .53. This is not surprising because adolescents sometimes display opposite sex trends at this young age when compared with adults. If sex differences emerge for E3: Assertiveness in adolescents, for example, girls appeared to score higher than boys, whereas the reverse was observed in college aged and adult individuals. Similarly, we found that girls score higher on C1: Competence at age 12 to 14 , whereas no such sex difference is observed in adulthood. However, with increasing age, sex differences found in adolescents tended to converge- - both with respect to direction and magnitude - toward those observed for self- and informant ratings in adulthood, with females scoring higher than males on most facets.

\section{Discussion}

This is the first study to report adolescent sex differences of FFM personality traits at the domain and facet levels, across 23 cultures that cover all inhabited continents of the world. Overall, the present study demonstrates that adult sex differences begin to appear in adolescence and that, with increasing age, sex differences found in adolescents tend to develop-both with respect to direction and magnitude-toward those observed for self- and informant ratings in adulthood, with females scoring higher than males on most traits. Our study further suggests that, as in adult-

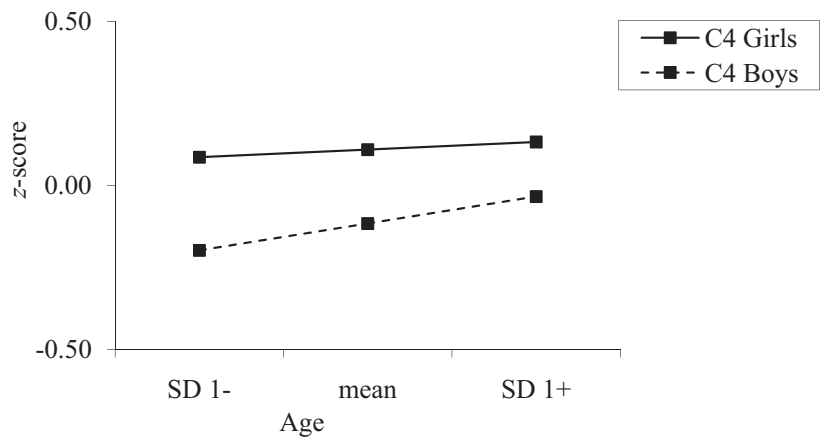

Figure 4. Predicted $z$ scores for C4: Achievement Striving for girls and boys aged 12 to 17 years. 
Table 3

Mean Z-Score Differences Between Females and Males on NEO Inventory Domains and Facets

\begin{tabular}{|c|c|c|c|c|c|c|c|c|c|c|}
\hline \multirow[b]{3}{*}{$\begin{array}{l}\text { NEO-PI-3/ } \\
\text { NEO-PI-R }\end{array}$} & \multirow{2}{*}{\multicolumn{6}{|c|}{ Adolescents (Observer ratings) }} & \multicolumn{4}{|c|}{ Adults } \\
\hline & & & & & & & \multicolumn{2}{|c|}{ Self-reports $(S)^{\mathrm{a}}$} & \multicolumn{2}{|c|}{ Observer ratings $(\mathrm{O})^{\mathrm{b}}$} \\
\hline & $\begin{array}{c}\text { Age } 12 \\
(n=471)\end{array}$ & $\begin{array}{c}\text { Age 13 } \\
(n=666)\end{array}$ & $\begin{array}{c}\text { Age } 14 \\
(n=1,147)\end{array}$ & $\begin{array}{c}\text { Age } 15 \\
(n=420)\end{array}$ & $\begin{array}{c}\text { Age } 16 \\
(n=715)\end{array}$ & $\begin{array}{c}\text { Age } 17 \\
(n=1,333)\end{array}$ & $\begin{array}{c}\text { College age } \\
(n=10,952)\end{array}$ & $\begin{array}{c}\text { adult } \\
(n=10,690)\end{array}$ & $\begin{array}{l}\text { College age } \\
(n=5,095)\end{array}$ & $\begin{array}{c}\quad \text { Adult } \\
(n=6,128)\end{array}$ \\
\hline $\mathrm{N}$ & -.01 & .09 & $.13^{*}$ & $.27^{*}$ & $.26^{* *}$ & $.21^{* * * *}$ & & & & \\
\hline $\mathrm{E}$ & $.17^{*}$ & .02 & .11 & $.23^{*}$ & $.22^{* *}$ & .07 & & & & \\
\hline $\mathrm{O}$ & $.29^{* * *}$ & $.25^{* *}$ & $.28^{* * * *}$ & $.36^{* * * * *}$ & $.34^{* * * *}$ & $.19^{* *}$ & & & & \\
\hline A & $.18^{*}$ & .05 & $.16^{* *}$ & .03 & .05 & $.23^{* * * *}$ & & & & \\
\hline $\mathrm{C}$ & $.36^{* * *}$ & $.30^{* * * *}$ & $.32^{\text {**** }}$ & $.27^{* *}$ & $.15^{*}$ & $.28^{* * * *}$ & & & & \\
\hline N1 & .10 & $.17^{*}$ & $.28^{\text {******* }}$ & $.29^{\text {*** }}$ & $.39^{* * * * *}$ & $.37^{* * * * *}$ & $.32^{* * * *}$ & $.43^{* * * *}$ & $.42^{* * * * *}$ & $.54^{* * * * *}$ \\
\hline N2 & .03 & .11 & .03 & $.25^{*}$ & $.22^{* * *}$ & .06 & $.16^{* * * *}$ & $.19^{* * * *}$ & $.15^{* * * * *}$ & -.02 \\
\hline N3 & -.02 & .02 & $.16^{\text {*** }}$ & $.23^{*}$ & $.23^{* *}$ & $.15^{* *}$ & $.17^{* * *}$ & $.29^{* * * *}$ & $.19^{* * * *}$ & $.29^{* * * *}$ \\
\hline $\mathrm{N} 4$ & .02 & .08 & .04 & .16 & .00 & $.19^{* * * *}$ & $.22^{* * * *}$ & $.23^{* * * *}$ & $.28^{* * * *}$ & $.31^{* * * *}$ \\
\hline N5 & -.14 & -.05 & -.01 & -.01 & .01 & -.04 & $.16^{* *}$ & $.11^{*}$ & -.01 & $-.11^{* * * *}$ \\
\hline N6 & -.04 & .06 & .08 & $.27^{* * *}$ & $.24^{* * *}$ & $.19^{\text {** }}$ & $.28^{* * * *}$ & $.36^{* * * * *}$ & $.29^{* * * * *}$ & $.34^{* * * *}$ \\
\hline E1 & $.25^{* *}$ & .03 & $.24^{* * * *}$ & $.22^{*}$ & $.22^{* * *}$ & $.12^{*}$ & $.24^{* * * *}$ & $.23^{* * * *}$ & $.11^{* * * *}$ & $.29^{* * * *}$ \\
\hline E2 & $.22^{*}$ & .14 & $.22^{* * * *}$ & $.43^{* * *}$ & $.29^{* * * *}$ & $.24^{* * * *}$ & $.20^{* * * *}$ & $.14^{* * * *}$ & $.15^{* * * *}$ & $.26^{* * * *}$ \\
\hline E3 & $.20^{*}$ & .11 & $.12^{*}$ & $.21^{*}$ & $.16^{*}$ & -.03 & $-.10^{*}$ & $-.27^{* * * *}$ & $-.07^{*}$ & $-.24^{* * *}$ \\
\hline E4 & .09 & $.16^{*}$ & -.01 & .06 & .10 & .03 & .04 & $.11^{*}$ & $.07^{*}$ & $.16^{* * * *}$ \\
\hline E5 & $-.22 * *$ & $-.32^{* * * *}$ & $-.30^{* * * *}$ & -.12 & -.14 & $-.31^{* * * *}$ & $-.18^{* * * *}$ & $-.38^{* * * *}$ & $-.17^{* * *}$ & $-.25^{* * * *}$ \\
\hline E6 & $.20^{*}$ & .01 & $.18^{\text {*** }}$ & .17 & $.33^{* * * *}$ & $.26^{* * * *}$ & $.27^{* * * * *}$ & $.16^{* * * * *}$ & $.17^{* * * * *}$ & $.26^{* * * *}$ \\
\hline $\mathrm{O} 1$ & -.08 & .00 & .05 & .04 & $.17^{*}$ & .07 & $.12^{* *}$ & .06 & $.06^{*}$ & $.10^{* * * *}$ \\
\hline $\mathrm{O} 2$ & $.73^{* * * * *}$ & $.46^{* * * * *}$ & $.50^{\text {******** }}$ & $.58^{* * * * *}$ & $.55^{* * * * *}$ & $.40^{* * * * *}$ & $.40^{* * * * *}$ & $.35^{\text {****** }}$ & $.26^{\text {****** }}$ & $.31^{* * * * * *}$ \\
\hline $\mathrm{O} 3$ & $.22^{* * *}$ & $.31^{* * * *}$ & $.38^{* * * *}$ & $.57^{* * * *}$ & $.38^{* * * *}$ & $.33^{* * * * *}$ & $.33^{* * * *}$ & $.31^{* * * * *}$ & $.26^{* * * * *}$ & $.42^{* * * *}$ \\
\hline $\mathrm{O} 4$ & .06 & .13 & .05 & .17 & $.16^{*}$ & .07 & $.11^{* *}$ & $.17^{* * *}$ & $.07^{*}$ & $.21^{* * * *}$ \\
\hline O5 & .02 & .02 & -.05 & -.07 & -.08 & $-.16^{* *}$ & $-.17^{* * * * *}$ & $-.16^{*}$ & $-.19^{* * * *}$ & $-.31^{* * * *}$ \\
\hline O6 & -.03 & -.03 & .05 & .07 & .04 & -.01 & $.15^{* * *}$ & .01 & -.02 & $.09^{* * *}$ \\
\hline $\mathrm{A} 1$ & $.18^{*}$ & .01 & .11 & -.04 & .11 & $.13^{*}$ & $.10^{*}$ & $.17^{* * * *}$ & $.08^{* *}$ & $.16^{* * * *}$ \\
\hline A2 & .03 & .02 & $.12^{*}$ & .01 & -.10 & $.19^{* * *}$ & $.34^{* * * *}$ & $.32^{* * * *}$ & $.09^{\text {*** }}$ & $.17^{* * * * *}$ \\
\hline A3 & $.24^{* * *}$ & .00 & .10 & -.01 & .03 & $.17^{* *}$ & $.25^{* * * *}$ & $.25^{* * * *}$ & $.10^{* * * *}$ & $.33^{* * * *}$ \\
\hline A4 & .04 & -.03 & .05 & -.14 & -.08 & .09 & .03 & $.17^{* * * * *}$ & .01 & $.17^{* * * * * *}$ \\
\hline A5 & -.04 & .01 & .09 & .10 & .07 & $.15^{* *}$ & $.22^{* * * * *}$ & $.22^{* * * * * *}$ & $.19^{* * * * *}$ & $.26^{* * * *}$ \\
\hline A6 & $.32^{* * * *}$ & $.25^{* *}$ & $.23^{* * * *}$ & $.30^{\text {*** }}$ & $.23^{* *}$ & $.29^{* * * *}$ & $.26^{* * * *}$ & $.28^{* * * *}$ & $.19^{* * * *}$ & $.39^{* * * *}$ \\
\hline $\mathrm{C} 1$ & $.20^{*}$ & $.15^{*}$ & $.14^{*}$ & .08 & -.02 & .11 & -.09 & -.10 & -.03 & $-.17^{* * * * *}$ \\
\hline $\mathrm{C} 2$ & $.25^{* *}$ & $.30^{* * * *}$ & $.33^{* * * * *}$ & $.36^{* * * *}$ & $.29^{* * * *}$ & $.36^{* * * *}$ & .09 & $.10^{* * *}$ & $.19^{* * * *}$ & $.24^{* * * *}$ \\
\hline $\mathrm{C} 3$ & $.37^{* * * *}$ & $.28^{* * * *}$ & $.33^{* * * * *}$ & $.26^{* *}$ & $.16^{*}$ & $.27^{* * * * *}$ & $.18^{* * * *}$ & $.13^{*}$ & $.13^{* * * *}$ & $.09^{* * * *}$ \\
\hline $\mathrm{C} 4$ & $.36^{* * *}$ & $.28^{* * * * *}$ & $.28^{* * * *}$ & .17 & .09 & $.21^{* * * * *}$ & .06 & -.04 & $.14^{\text {***** }}$ & $-.12^{* * * *}$ \\
\hline C5 & $.33^{* * * *}$ & $.30^{* * * *}$ & $.24^{* * * *}$ & $.24^{*}$ & .11 & $.25^{* * * *}$ & $.09^{*}$ & .04 & $.14^{* * * *}$ & $.05^{*}$ \\
\hline C6 & $.30^{* * *}$ & $.20^{*}$ & $.27^{* * * * *}$ & $.22^{*}$ & .08 & $.16^{* *}$ & -.04 & -.06 & $.10^{* * * * *}$ & -.02 \\
\hline
\end{tabular}

Note. Across the 23 cultures that were included in the present study, 98 cases had missing values for age. Gender differences $=$ females - males. NEO-PI-3 = NEO Personality Inventory-3; NEO-PI-R = Revised NEO Personality Inventory; N = Neuroticism; E = Extraversion; O = Openness; A = Agreeableness; C = Conscientiousness; N1 = Anxiety; N2 = Angry Hostility; N3 = Depression; N4 = Self-Consciousness; N5 = Impulsiveness; N6 = Vulnerability; E1 = Warmth; E2 = Gregariousness; E3 = Assertiveness; E4 = Activity; E5 = Excitement-Seeking; E6 = Positive Emotions; $\mathrm{O} 1=$ Fantasy; $\mathrm{O} 2=$ Aesthetics; $\mathrm{O} 3=$ Feelings; $\mathrm{O} 4=$ Actions; O5 = Ideas; O6 = Values; A1 = Trust; A2 = Straightforwardness; A3 = Altruism; A4 = Compliance; A5 = Modesty; A6 = Tender-Mindedness; C1 = Competence; C2 = Order; C3 = Dutifulness; C4 = Achievement Striving; C5 = Self-Discipline; C6 = Deliberation.

${ }^{a}$ From Costa, Terracciano, and McCrae (2001). ${ }^{b}$ From McCrae and Terracciano (2005b). College-aged individuals are 18 to 21 years old, and adult individuals are $40+$ years old. Domain scores were not reported in Costa et al. (2001) or McCrae et al. (2005).

${ }^{*} p<.05 .^{* * *} p<.01 .^{* * * *} p<.001$.

hood, sex differences in adolescence are modest in magnitude and generalize across cultures.

The cross-sectional examination of how sex differences unfold in 12- to 17-year-old adolescents enabled us to investigate age as a possible source of inconsistencies that characterize the literature on sex differences in adolescents' personality. Our study suggests that with increasing age, the sex difference in N, N1: Anxiety, N6: Vulnerability, E6: Positive Emotions, and O5: Ideas becomes larger, and that adolescent boys and girls converge with respect to E3: Assertiveness, O2: Aesthetics, and C4: Achievement Striving. These findings put some of the seemingly contradictory findings from earlier studies into perspective. More specifically, some researchers (Branje et al., 2007; Costa et al., 2008) found no sex difference for N, whereas others did (Klimstra et al., 2009; McCrae, Costa, et al., 2005). Both sets of results are consistent with the present finding that the sex difference for $\mathrm{N}$ emerges at age 14, as studies that found no sex difference for $\mathrm{N}$ have typically used younger samples (Branje et al., 2007; Costa et al., 2008) compared with the studies that did find a sex difference for $\mathrm{N}$ (Klimstra et al., 2009; McCrae, Costa, et al., 2005). Furthermore, some have reported that girls score higher on $\mathrm{C}$ than boys (Klimstra et al., 2009; McCrae, Costa, et al., 2005), whereas others could not find a sex difference for this personality trait (McCrae et al., 2002). In the present study, girls scored higher than boys for $\mathrm{C}$ and its facets 
Table 4

Correlations Between Adolescent, College-Aged, and Adult Mean Z-Score Differences Across Facets

\begin{tabular}{|c|c|c|c|c|c|c|c|c|c|c|}
\hline \multirow[b]{3}{*}{$\begin{array}{l}\text { NEO-PI-3/ } \\
\text { NEO-PI-R }\end{array}$} & \multirow{2}{*}{\multicolumn{6}{|c|}{ Adolescents (observer ratings) }} & \multicolumn{4}{|c|}{ Adults } \\
\hline & & & & & & & \multicolumn{2}{|c|}{ Self-reports $(S)^{\mathrm{a}}$} & \multicolumn{2}{|c|}{ Observer ratings $(\mathrm{O})^{\mathrm{b}}$} \\
\hline & $\begin{array}{l}\text { Age 12 } \\
(n=471)\end{array}$ & $\begin{array}{c}\text { Age } 13 \\
(n=666)\end{array}$ & $\begin{array}{c}\text { Age 14 } \\
(n=1,147)\end{array}$ & $\begin{array}{l}\text { Age 15 } \\
(n=420)\end{array}$ & $\begin{array}{l}\text { Age 16 } \\
(n=715)\end{array}$ & $\begin{array}{c}\text { Age 17 } \\
(n=1,333)\end{array}$ & $\begin{array}{c}\text { College age } \\
(n=10,952)\end{array}$ & $\begin{array}{c}\text { Adult } \\
(n=10,690)\end{array}$ & $\begin{array}{l}\text { College age } \\
(n=5,095)\end{array}$ & $\begin{array}{c}\text { Adult } \\
(n=6,128)\end{array}$ \\
\hline
\end{tabular}

Age $12 \quad 1.00$

Age 13

Age 14

Age 15

Age 16

Age 17

College $(\mathrm{S})$

Adult (S)

$$
.83^{* * * *}
$$

$.84^{\text {**** }}$

$.62^{\text {**** }}$

$.55^{\text {*** }}$

$67^{\text {**** }}$

.28

.19

College (O)

.19
.34

Adult (O)

1.00
$.86^{\text {**** }}$
$.78^{\text {**** }}$
$.62^{\text {**** }}$
$.76^{\text {**** }}$
.33
.32
$.53^{\text {*** }}$
.29

$$
\begin{aligned}
& 1.00 \\
& .80^{* * *} \\
& .73^{* * *} \\
& .88^{* * *} \\
& .53^{*} \\
& .47^{* *} \\
& .63^{* * *} \\
& .47^{* *}
\end{aligned}
$$

$\begin{array}{ll}1.00 & \\ .87^{\text {*** }} & 1.00 \\ .73^{\text {*** }} & .70^{\text {*** }} \\ .53^{\text {** }} & .60^{\text {*** }} \\ .42^{* * * *} & .53^{\text {** }} \\ .68^{\text {*** }} & .70^{\text {**** }} \\ .48^{\text {** }} & .60^{\text {*** }}\end{array}$

$$
\begin{aligned}
& 1.00 \\
& .72^{* * * *} \\
& .71^{* * * *} \\
& .86^{* * *} \\
& .73^{* * *}
\end{aligned}
$$

$$
\begin{aligned}
& 1.00 \\
& .91^{* * * *} \\
& .79^{* * *} \\
& .84^{* * * *}
\end{aligned}
$$

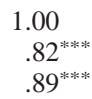$$
1.00
$$

$.84^{\text {**** }}$

Note. Across the 23 cultures that were included in the present study, 98 cases had missing values for age. Gender differences $=$ females - males. NEO-PI-3 = NEO Personality Inventory-3; NEO-PI-R = Revised NEO Personality Inventory; $\mathrm{N}=\mathrm{Neuroticism}$; E = Extraversion; O = Openness; A = Agreeableness; $\mathrm{C}=$ Conscientiousness; N1 = Anxiety; N2 = Angry Hostility; N3 = Depression; N4 = Self-Consciousness; N5 = Impulsiveness; N6 = Vulnerability; E1 = Warmth; E2 = Gregariousness; E3 = Assertiveness; E4 = Activity; E5 = Excitement-Seeking; E6 = Positive Emotions; $\mathrm{O} 1=$ Fantasy; O2 = Aesthetics; O3 = Feelings; O4 = Actions; O5 = Ideas; O6 = Values; A1 = Trust; A2 = Straightforwardness; A3 = Altruism; A4 = Compliance; A5 = Modesty; A6 = Tender-Mindedness; $\mathrm{C} 1=$ Competence; $\mathrm{C} 2=$ Order; $\mathrm{C} 3=\mathrm{Dutifulness}$; $\mathrm{C} 4=\mathrm{Achievement}$ Striving; C5 = Self-Discipline; C6 = Deliberation.

${ }^{a}$ From Costa, Terracciano, and McCrae (2001). ${ }^{\text {b }}$ From McCrae and Terracciano (2005b). College-aged individuals are 18 to 21 years old, and adult individuals are 40+ years old. Domain scores were not reported in Costa et al. (2001) or McCrae et al. (2005).

${ }^{*} p<.05$. ** $p<.01$. **** $p<.001$.

from age 12 onward, but both sexes tended to converge when moving toward adulthood (although this trend was only significant for C4: Achievement Striving). As significant age effects were also found for facets of $\mathrm{E}$ and $\mathrm{O}$, differences in age distributions between previously published studies might be responsible for inconsistent findings with respect to these personality traits as well (Soto et al., 2011).

As hypothesized, and in line with the biological changes that are thought to be underlying the sex gap in internalizing problems (i.e., depression), girls begin to score higher than boys on $\mathrm{N}$ and its facets from age 14 onward. Most sex differences for the facets of A (with girls scoring higher than boys) emerge at age 17, although girls already score higher than boys by age 12 on A6: TenderMindedness. The latter suggests that the intensification of affiliative orientation in girls between age 11 to 13 years is predominantly associated with A6: Tender-Mindedness and, to a lesser extent, with the other facets of A. The picture for $\mathrm{E}$ is somewhat more differentiated, as this component consists of an energy component and an interpersonal component. As hypothesized, girls are found to score higher than boys on the interpersonal or affiliative facets (E1: Warmth, E2: Gregariousness, E3: Assertiveness) already by age 12 . Less consistent sex differences are found for the energy facets (E4: Activity, E5: Excitement-Seeking, E6: Positive Emotions). Although we hypothesized that sex differences on these facets would emerge round age 14, boys already score higher on E5: Excitement-Seeking from age 12 onward, but adolescent girls score consistently higher than boys on E6: Positive Emotions from age 16 onward. No substantial sex differences between age 12 and 17 were observed for E4: Activity. Furthermore, the present study shows that although girls tend to be higher on $\mathrm{C}$ and its facets across the entire period of 12 to 17 years, more (substantial) sex differences for these personality traits occur in 12- to 14-year- old than in 15- to 17-year-old adolescents. The finding that boys tend to catch up with girls in personality development (also reported by Klimstra \& colleagues, 2009) parallels the tendency that girls are generally ahead of boys in intellectual and cognitive functioning (e.g., executive functioning) during early adolescent years, but that boys tend to catch up at later adolescent age. Finally, although it has been demonstrated that intelligence and $\mathrm{O}$ share additive genetic effects (Bratko et al., 2012), the development of sex differences for $\mathrm{O}$ does not mirror the emergence of the sex gap in intellectual development observed in adolescence. In our study, we find that adolescent girls are higher than boys on $\mathrm{O}$ from age 12 onward, and that this sex difference mainly rests on sex differences for O2: Aesthetics and O3: Feelings. The masculine-typed effect for O5: Ideas begins to show by age 17.

Overall, our findings are in line with Costa et al.'s (2008) argument that adolescent girls start to display higher levels of sex-typed personality traits at an earlier age than boys, and connects with the commonly observed sex gap in pubertal timing or cerebral cortical development. More specifically, girls are found to undergo a faster acceleration in cerebral cortical development during early adolescence than boys and remain in advance of boys until 14 to 15 years (Colom \& Lynn, 2004). In addition, girls have been shown to be ahead, on average, with respect to pubertal timing (Petersen, Crockett, Richards, \& Boxer, 1988). These differences in cerebral cortical development or pubertal timing might explain why girls tend to display higher levels of sex-typed personality traits at an earlier age than boys.

The findings of the present study further underscore that facets within a domain may sometimes show different trends in adolescents, as they do in adults (Costa et al., 2001; McCrae \& Terracciano, 2005a). In addition, the results show that these facet-level sex differences may be different in adolescence than in adulthood. 
Before age 17, for instance, boys tend to score as high as girls on several facets (i.e., N4, O1, O4, A1, A2, A5) on which adult women typically score higher than adult men. Furthermore, whereas adult men typically score higher than adult women on E3: Assertiveness, we found exactly the opposite pattern in adolescence, with girls scoring higher than boys. In addition, the sex difference for O5: Ideas (with males scoring higher than females) that is typically found in adulthood becomes significant in adolescence only from age 17. This illustrates that research at the domain level can provide only a rough sketch-not a complete picture (Soto et al., 2011).

Overall, the magnitude of the sex differences for the FFM domains and facets in the different cultures were relatively small (with most sex differences smaller than one-quarter standard deviation and only few larger than one-half standard deviation), consistent with what is observed in adulthood. Also as in studies of adults (e.g., Bleidorn et al., 2013; Schmitt et al., 2008), we found some suggestion that the magnitude of sex differences varied across cultures, with larger differences in prosperous and egalitarian cultures. In general, however, the pattern of sex differences was similar across cultures.

Our results also have implications for practical settings. It has been repeatedly demonstrated that girls tend to be more successful than boys during elementary and secondary education, even in math and science, which are traditionally considered to be masculine subjects (Demie, 2001; Mills, Martino, \& Lingard, 2004). Children's learning and their success in school depends not only on their cognitive ability or intelligence but also on their personality. More specifically, academic performance significantly correlates with $\mathrm{A}, \mathrm{C}$, and $\mathrm{O}$, even when controlling for intelligence (Poropat, 2009) or executive functioning (Neuenschwander, Cimeli, Röthlisberger, \& Roebers, 2013). For example, Mervielde, Buyst, and De Fruyt (1995) found significant correlations between $\mathrm{O}, \mathrm{E}$, and $\mathrm{C}$ and academic performance in both first and second graders (See also De Fruyt, Van Leeuwen, De Bolle, \& De Clercq, 2008).

Our findings demonstrate that adolescent girls consistently score higher than boys on personality traits that are found to facilitate academic achievement, at least within the current school climate. Stated differently, the current school environment or climate might be, in general, more attuned to feminine-typed personalities, which make it, in general, easier for girls to achieve better grades at school.

Particular limitations should be taken into account when interpreting the present findings and designing future research. First, a relatively small number of Level 2 units (i.e., 23) was included in the current study. Although this Level 2 sample size is sufficient to estimate regression coefficients and the variance components, as well as the standard errors of the regression coefficients without bias, the standard errors for the Level 2 variance components might be less accurate (i.e., these standard errors might already be underestimated in analyses with $N=30$ at Level 2; Maas \& Hox, 2005). As such, some prudence is in order when interpreting the between-culture variance of sex, and additional studies - that include a broader range of cultures-are needed to support our confidence in the present Level 2 findings. Second, we used samples of convenience, whereas-ideally_nationally representative samples would be obtained. Third, the present study uses a cross-sectional design, whereas longitudinal studies could provide stronger data on the emergence of sex differences. Fourth, the present study examined only two possible sources (i.e., culture and age) of inconsistent findings reported by previous studies, leaving other possible sources of inconsistent findings (e.g., different measures) uninvestigated. Finally, personality data were collected by undergraduate psychology students, which may limit the generalizability of the current findings. Informant reports, in general, and personality ratings produced by undergraduate students-in particular, used in the present study-are, like self-ratings, susceptible to certain biases or distortions. Wood, Harms, and Vazire (2010), for instance, demonstrated that informant reports are influenced by the informant's own personality. Future studies should therefore be multi-instrument (e.g., administering both the NEO-PI-3 and the Big Five Inventory; John, Donahue, \& Kentle, 1991) and also multimethod (including self-reports and ratings from different classes of raters, e.g., parents and peers).

Despite these limitations, the present study contributes to the literature on sex differences in several ways. First, it reports on cross-cultural FFM sex differences in the personality of adolescents aged 12 to 17 years from 23 cultures across the globe, including both English and non-English speaking countries. Second, the study investigated informant ratings of adolescents' personality traits, thereby supplementing previous cross-cultural studies (Soto et al., 2011) on self-reported sex differences in adolescence. Third, the current study used standardized procedures of data collection across all participating cultures, contributing to the reliability of the present findings. Fourth, we used an adolescentfriendly version of the NEO-PI-R (i.e., NEO-PI-3) to assess personality traits in adolescents. Given that the NEO-PI-3 and NEOPI-R (Costa \& McCrae, 1992) have the same scales, with a largely common item set and an identical hierarchical structure (McCrae, Costa, et al., 2005), their means are directly comparable at the cultural level (De Fruyt et al., 2009). In addition, the current study demonstrated full uniqueness invariance across the NEO-PI-3 and NEO-PI-R for N, E, O, A, and C. As such, we were able to meaningfully compare NEO-PI-3 informant ratings for adolescents with the self-and informant-rated adult NEO-PI-R data that have been reported as part of the PPOC project. Fifth, sex differences were investigated at both the broad domain and the more finegrained facet level of the personality trait hierarchy, offering a more complete account of sex differences in personality.

In conclusion, the present study indicates that culture is probably not a substantial source of the inconsistencies that characterize the literature on sex differences in adolescents' personality. Age, by contrast, was found to significantly affect sex differences for several personality traits. The latter may explain why previous studies that included different age groups or focused on different age ranges in adolescence reported conflicting sex differences for adolescent personality traits. Furthermore, the present study illustrates that, with increasing age, sex differences found in adolescents tend to develop-both with respect to direction and magnitude-toward those observed in adulthood, with females scoring higher than males on most traits. Finally, it appears that girls begin to display sextyped personality traits at an earlier age than boys. 


\section{References}

Ackerman, S. J., \& Hilsenroth, M. J. (2003). A review of therapist characteristics and techniques positively impacting the therapeutic alliance. Clinical Psychology Review, 23, 1-33. http://dx.doi.org/10.1016/S02727358(02)00146-0

Aiken, L. S., \& West, S. G. (1991). Multiple regression: Testing and interpreting interactions. Newbury Park, CA: Sage.

Allik, J., Laidra, K., Realo, A., \& Pullmann, H. (2004). Personality development from 12 to 18 years of age: Changes in mean levels and structure of traits. European Journal of Personality, 18, 445-462. http://dx.doi .org/10.1002/per.524

Anderson, V. A., Anderson, P., Northam, E., Jacobs, R., \& Catroppa, C. (2001). Development of executive functions through late childhood and adolescence in an Australian sample. Developmental Neuropsychology, 20, 385-406. http://dx.doi.org/10.1207/S15326942DN2001_5

Angold, A., Costello, E. J., Erkanli, A., \& Worthman, C. M. (1999). Pubertal changes in hormone levels and depression in girls. Psychological Medicine, 29, 1043-1053. http://dx.doi.org/10.1017/S0033291799008946

Angold, A., Costello, E. J., \& Worthman, C. M. (1998). Puberty and depression: The roles of age, pubertal status and pubertal timing. Psychological Medicine, 28, 51-61. http://dx.doi.org/10.1017/ S003329179700593X

Angold, A., \& Worthman, C. W. (1993). Puberty onset of gender differences in rates of depression: A developmental, epidemiologic and neuroendocrine perspective. Journal of Affective Disorders, 29, 145-158. http://dx.doi.org/10.1016/0165-0327(93)90029-J

Ashton, M. C., Jackson, D. N., Paunonen, S. V., Helmes, E., \& Rothstein, M. G. (1995). The criterion validity of broad factor scales versus specific facet scales. Journal of Research in Personality, 29, 432-442. http://dx .doi.org/10.1006/jrpe.1995.1025

Blakemore, S.-J., Burnett, S., \& Dahl, R. E. (2010). The role of puberty in the developing adolescent brain. Human Brain Mapping, 31, 926-933. http://dx.doi.org/10.1002/hbm.21052

Bleidorn, W., Klimstra, T. A., Denissen, J. J. A., Rentfrow, P. J., Potter, J., \& Gosling, S. D. (2013). Personality maturation around the world: A cross-cultural examination of social-investment theory. Psychological Science, 24, 2530-2540. http://dx.doi.org/10.1177/0956797613498396

Branje, S. J. T., Van Lieshout, C. F. M., \& Gerris, J. R. M. (2007). Big Five personality development in adolescence and adulthood. European Journal of Personality, 21, 45-62. http://dx.doi.org/10.1002/per.596

Bratko, D., Butkovic, A., Vukasovic, T., Chamorro-Premuzic, T., \& von Stumm, S. (2012). Cognitive ability, self-assessed intelligence and personality: Common genetic but independent environmental aetiologies. Intelligence, 40, 91-99. http://dx.doi.org/10.1016/j.intell.2012.02.001

Buss, D. M. (1995). Psychological sex differences: Origins through sexual selection. American Psychologist, 50, 164-168. http://dx.doi.org/ 10.1037/0003-066X.50.3.164

Buss, D. M. (1997). Evolutionary foundations of personality. In R. Hogan (Ed.), Handbook of personality psychology (pp. 317-344). London, UK: Academic Press. http://dx.doi.org/10.1016/B978-012134645-4/50014-7

Colom, R., \& Lynn, R. (2004). Testing the developmental theory of sex differences in intelligence on 12-18 year olds. Personality and Individual Differences, 36, 75-82. http://dx.doi.org/10.1016/S01918869(03)00053-9

Costa, P. T., Jr., \& McCrae, R. R. (1992). Normal personality assessment in clinical practice: The NEO Personality Inventory. Psychological Assessment, 16, 576-584.

Costa, P. T., Jr., \& McCrae, R. R. (1995). Domains and facets: Hierarchical personality assessment using the revised NEO personality inventory. Journal of Personality Assessment, 64, 21-50. http://dx.doi.org/10.1207/ s15327752jpa6401_2

Costa, P. T. J., Jr., McCrae, R. R., \& Martin, T. A. (2008). Incipient adult personality: The NEO-PI-3 in middle-school-aged children. British
Journal of Developmental Psychology, 26, 71-89. http://dx.doi.org/ 10.1348/026151007X196273

Costa, P. T., Jr., Terracciano, A., \& McCrae, R. R. (2001). Gender differences in personality traits across cultures: Robust and surprising findings. Journal of Personality and Social Psychology, 81, 322-331. http://dx.doi.org/10.1037/0022-3514.81.2.322

Cyranowski, J. M., Frank, E., Young, E., \& Shear, M. K. (2000). Adolescent onset of the gender difference in lifetime rates of major depression: A theoretical model. Archives of General Psychiatry, 57, 21-27. http:// dx.doi.org/10.1001/archpsyc.57.1.21

De Bolle, M., Beyers, W., De Clercq, B., \& De Fruyt, F. (2012). General personality and psychopathology in referred and nonreferred children and adolescents: An investigation of continuity, pathoplasty, and complication models. Journal of Abnormal Psychology, 121, 958-970. http://dx.doi.org/10.1037/a0027742

De Fruyt, F., De Bolle, M., McCrae, R. R., Terracciano, A., \& Costa, P. T., Jr., \& the Collaborators of the Adolescent Personality Profiles of Cultures Project. (2009). Assessing the universal structure of personality in early adolescence: The NEO-PI-R and NEO-PI-3 in 24 cultures. Assessment, 16, 301-311. http://dx.doi.org/10.1177/1073191109333760

De Fruyt, F., Van Leeuwen, K., De Bolle, M., \& De Clercq, B. (2008). Sex differences in school performance as a function of conscientiousness, imagination and the mediating role of problem behaviour. European Journal of Personality, 22, 167-184. http://dx.doi.org/10.1002/per.675

Demie, F. (2001). Ethnic and gender differences in educational achievement and implications for school improvement strategies. Educational Research, 43, 91-106. http://dx.doi.org/10.1080/00131880110040968

DeYoung, C. G., Quilty, L. C., \& Peterson, J. B. (2007). Between facets and domains: 10 aspects of the Big Five. Journal of Personality and Social Psychology, 93, 880-896. http://dx.doi.org/10.1037/0022-3514 93.5.880

Eagly, A. H. (1987). Sex differences in social behavior: A social-role interpretation. Hillsdale, NJ: Erlbaum.

Funder, D. C., \& Colvin, C. R. (1997). Congruence of self and others' judgments of personality. In J. A. J. R. Hogan \& S. R. Briggs (Eds.), Handbook of personality psychology (pp. 617-647). Orlando, FL: Academic Press. http://dx.doi.org/10.1016/B978-012134645-4/50025-1

Fuster, J. M. (2001). The prefrontal cortex-An update: Time is of the essence. Neuron, 30, 319-333. http://dx.doi.org/10.1016/S08966273(01)00285-9

Fuster, J. M. (2002). Frontal lobe and cognitive development. Journal of Neurocytology, 31, 373-385. http://dx.doi.org/10.1023/A 1024190429920

Guimond, S., Branscombe, N. R., Brunot, S., Buunk, A. P., Chatard, A., Désert, M., . . . Yzerbyt, V. (2007). Culture, gender, and the self: Variations and impact of social comparison processes. Journal of Personality and Social Psychology, 92, 1118-1134. http://dx.doi.org/ 10.1037/0022-3514.92.6.1118

Herdt, G. H. (Ed.), (1982). Rituals of manhood: Male initiation in Papua New Guinea. Berkeley, CA: University of California Press.

Hunter, F. T., \& Youniss, J. (1982). Changes in functions of three relations during adolescence. Developmental Psychology, 18, 806-811. http://dx doi.org/10.1037/0012-1649.18.6.806

John, O. P., Donahue, E. M., \& Kentle, R. L. (1991). The Big Five Inventory-Versions 4a and 54. Berkeley, CA: University of California, Berkeley, Institute of Personality and Social Research.

Klimstra, T. A., Hale, W. W., Raaijmakers, Q. A., Branje, S. J. T., \& Meeus, W. H. J. (2009). Maturation of personality in adolescence. Journal of Personality and Social Psychology, 96, 898-912. http://dx .doi.org/10.1037/a0014746

Larson, R., \& Richards, M. H. (1989). Introduction: The changing life space of early adolescence. Journal of Youth and Adolescence, 18, 501-509. http://dx.doi.org/10.1007/BF02139070 
Lenroot, R. K., \& Giedd, J. N. (2010). Sex differences in the adolescent brain. Brain and Cognition, 72, 46-55. http://dx.doi.org/10.1016/j.bandc .2009 .10 .008

Lorenzo-Seva, U., \& ten Berge, J. M. F. (2006). Tucker's congruence coefficient as a meaningful index of factor similarity. Methodology, 2, $57-64$.

Maas, C. J. M., \& Hox, J. J. (2005). Sufficient sample sizes for multilevel modeling. Methodology: European Journal of Research Methods for the Behavioral and Social Sciences, 1, 86-92.

Maccoby, E. E., \& Jacklin, C. N. (1987). Gender segregation in childhood. Advances in Child Development and Behavior, 20, 239-287. http://dx .doi.org/10.1016/S0065-2407(08)60404-8

Marshall, W. A., \& Tanner, J. M. (1986). Puberty. In F. Falkner \& J. M. Tanner (Eds.), Human growth (Vol. 11, pp. 171-209). New York, NY: Plenum Press.

McCrae, R. R., \& Costa, P. T. J. (2008). The Five-Factor Theory of personality. In O. P. John, R. W. Robins, \& L. A. Pervin (Eds.), Handbook of personality: Theory and research (3rd ed., pp. 159-181). New York, NY: Guilford Press.

McCrae, R. R., \& Costa, P. T. J. (2010). NEO Inventories: Professional manual. Lutz, FL: Psychological Assessment Resources.

McCrae, R. R., Costa, P. T., Jr., \& Martin, T. A. (2005). The NEO-PI-3: A more readable revised NEO Personality Inventory. Journal of Personality Assessment, 84, 261-270. http://dx.doi.org/10.1207/ s15327752jpa8403_05

McCrae, R. R., Costa, P. T., Jr., Terracciano, A., Parker, W. D., Mills, C. J., De Fruyt, F., \& Mervielde, I. (2002). Personality trait development from age 12 to age 18: Longitudinal, cross-sectional, and cross-cultural analyses. Journal of Personality and Social Psychology, 83, 1456-1468. http://dx.doi.org/10.1037/0022-3514.83.6.1456

McCrae, R. R., \& Terracciano, A. (2005a). Personality profiles of cultures: Aggregate personality traits. Journal of Personality and Social Psychology, 89, 407-425. http://dx.doi.org/10.1037/0022-3514.89.3.407

McCrae, R. R., \& Terracciano, A. (2005b). Universal features of personality traits from the observer's perspective: Data from 50 cultures. Journal of Personality and Social Psychology, 88, 547-561. http://dx .doi.org/10.1037/0022-3514.88.3.547

McCrae, R. R., Terracciano, A., De Fruyt, F., De Bolle, M., Gelfand, M. J., Costa, P. T., \& 42 collaborators of the APPOC project (2010). The validity and structure of culture-level personality scores: Data from ratings of young adolescents. Journal of Personality, 78, 815-838. http://dx.doi.org/10.1111/j.1467-6494.2010.00634.x

Mervielde, I., Buyst, V., \& De Fruyt, F. (1995). The validity of the Big Five as a model for teachers ratings of individual differences among children aged 4-12 years. Personality and Individual Differences, 18, 525-534. http://dx.doi.org/10.1016/0191-8869(94)00175-R

Mills, M., Martino, W., \& Lingard, B. (2004). Attracting, recruiting and retaining male teachers: Policy issues in the male teacher debate. British Journal of Sociology of Education, 25, 355-369. http://dx.doi.org/ $10.1080 / 0142569042000216990$

Moutafi, J., Furnham, A., \& Paltiel, L. (2005). Can personality factors predict intelligence? Personality and Individual Differences, 38, 10211033. http://dx.doi.org/10.1016/j.paid.2004.06.023

Neuenschwander, R., Cimeli, P., Röthlisberger, M., \& Roebers, C. M. (2013). Personality factors in elementary school children: Contributions to academic performance over and above executive functions? Learning and Individual Differences, 25, 118-125. http://dx.doi.org/10.1016/j .lindif.2012.12.006

Petersen, A. C., Crockett, L., Richards, M., \& Boxer, A. (1988). A self-report measure of pubertal status: Reliability, validity, and initial norms. Journal of Youth and Adolescence, 17, 117-133. http://dx.doi .org/10.1007/BF01537962

Poropat, A. E. (2009). A meta-analysis of the five-factor model of personality and academic performance. Psychological Bulletin, 135, 322-338. http://dx.doi.org/10.1037/a0014996

Pullmann, H., Raudsepp, L., \& Allik, J. (2006). Stability and change in adolescents' personality: A longitudinal study. European Journal of Personality, 20, 447-459. http://dx.doi.org/10.1002/per.611

Rice, K. G., \& Mulkeen, P. (1995). Relationships with parents and peers: A longitudinal study of adolescent intimacy. Journal of Adolescent Research, 10, 338-357. http://dx.doi.org/10.1177/0743554895103003

Roberts, B. W., Walton, K. E., \& Viechtbauer, W. (2006). Patterns of mean-level change in personality traits across the life course: A metaanalysis of longitudinal studies. Psychological Bulletin, 132, 1-25. http://dx.doi.org/10.1037/0033-2909.132.1.1

Schmitt, D. P., Realo, A., Voracek, M., \& Allik, J. (2008). Why can't a man be more like a woman? Sex differences in Big Five personality traits across 55 cultures. Journal of Personality and Social Psychology, 94, 168-182. http://dx.doi.org/10.1037/0022-3514.94.1.168

Silberman, M. A., \& Snarey, J. (1993). Gender differences in moral development during early adolescence: The contribution of sex-related variations in maturation. Current Psychology: A Journal for Diverse Perspectives on Diverse Psychological Issues, 12, 163-171. http://dx .doi.org/10.1007/BF02686821

Soto, C. J., John, O. P., Gosling, S. D., \& Potter, J. (2008). The developmental psychometrics of big five self-reports: Acquiescence, factor structure, coherence, and differentiation from ages 10 to 20. Journal of Personality and Social Psychology, 94, 718-737. http://dx.doi.org/ 10.1037/0022-3514.94.4.718

Soto, C. J., John, O. P., Gosling, S. D., \& Potter, J. (2011). Age differences in personality traits from 10 to 65: Big Five domains and facets in a large cross-sectional sample. Journal of Personality and Social Psychology, 100, 330-348. http://dx.doi.org/10.1037/a0021717

Susman, E. J., Nottelmann, E. D., Inoff-Germain, G., Dorn, L. D., \& Chrousos, G. P. (1987). Hormonal influences on aspects of psychological development during adolescence. Journal of Adolescent Health Care: Official Publication of the Society for Adolescent Medicine, 8, 492-504. http://dx.doi.org/10.1016/0197-0070(87)90050-7

Terracciano, A., McCrae, R. R., Brant, L. J., \& Costa, P. T., Jr. (2005). Hierarchical linear modeling analyses of the NEO-PI-R scales in the Baltimore Longitudinal Study of Aging. Psychology and Aging, 20, 493-506. http://dx.doi.org/10.1037/0882-7974.20.3.493

Wood, D., Harms, P., \& Vazire, S. (2010). Perceiver effects as projective tests: What your perceptions of others say about you. Journal of Personality and Social Psychology, 99, 174-190. http://dx.doi.org/10.1037/ $\mathrm{a} 0019390$

Received September 26, 2013

Revision received August 11, 2014

Accepted October 23, 2014 